IZA DP No. 9166

Urban Spatial Structure, Employment and Social Ties: European versus American Cities

Pierre M. Picard

Yves Zenou

July 2015 


\title{
Urban Spatial Structure, Employment and Social Ties: European versus American Cities
}

\author{
Pierre M. Picard \\ CREA, University of Luxemburg, \\ CORE, Université Catholique de Louvain and IZA
}

Yves Zenou

Stockholm University,

IFN, CEPR and IZA

\section{Discussion Paper No. 9166 \\ July 2015}

\author{
IZA \\ P.O. Box 7240 \\ 53072 Bonn \\ Germany
}

Phone: +49-228-3894-0

Fax: +49-228-3894-180

E-mail: iza@iza.org

Any opinions expressed here are those of the author(s) and not those of IZA. Research published in this series may include views on policy, but the institute itself takes no institutional policy positions. The IZA research network is committed to the IZA Guiding Principles of Research Integrity.

The Institute for the Study of Labor (IZA) in Bonn is a local and virtual international research center and a place of communication between science, politics and business. IZA is an independent nonprofit organization supported by Deutsche Post Foundation. The center is associated with the University of Bonn and offers a stimulating research environment through its international network, workshops and conferences, data service, project support, research visits and doctoral program. IZA engages in (i) original and internationally competitive research in all fields of labor economics, (ii) development of policy concepts, and (iii) dissemination of research results and concepts to the interested public.

IZA Discussion Papers often represent preliminary work and are circulated to encourage discussion. Citation of such a paper should account for its provisional character. A revised version may be available directly from the author. 
IZA Discussion Paper No. 9166

July 2015

\section{ABSTRACT}

\section{Urban Spatial Structure, Employment and Social Ties: European versus American Cities*}

We develop a model where workers both choose their residential location (geographical space) and their social interactions (social space). In equilibrium, we show under which condition some individuals reside close to the job center while others live far away from it. Even though the two populations have the same characteristics and no group experiences any discrimination, we show that the majority group always has a lower unemployment rate than the minority group both when ethnic minorities reside close and far away from the citycenter where jobs are located. This is because they have a larger and better-quality social network. This result is quite unique as it can explain the high unemployment rates of ethnic minorities both in European and American cities.

JEL Classification: A14, J15, R14, Z13

Keywords: $\quad$ social interactions, segregation, labor market, spatial mismatch, network size

Corresponding author:

Yves Zenou

Stockholm University

Department of Economics

10691 Stockholm

Sweden

E-mail: yves.zenou@ne.su.se

\footnotetext{
* Yves Zenou gratefully acknowledges the financial support from the French National Research Agency grant ANR-2011-BSH1-014-01.
} 


\section{Introduction}

Economists have long been interested in how the socio-economic outcomes of individuals are shaped by their interactions with those around them. This question is especially important in urban areas where cities provide the homes, workplaces, and social environments for most individuals and families and present a substantial stratification across ethnic groups.

The aim of this paper is to analyze the relationship between workers' social interactions and their labor-market outcomes in an urban spatial framework and analyze how minority and majority workers are differently affected.

To be more precise, we develop a simple model where there are frictions in the labor market and where, in order to find a job, workers need to interact with each other. They have to decide on how much time they want to spend with other workers. For each social interaction, the worker needs to commute to the location of the other worker. There is therefore a trade off since the more time they spend with other workers, the higher is their chance of finding a job but the more costly it is. We consider a closed and linear city where all jobs are located in the job center -or Central Business District (CBD). In the homogenous population case, we show that workers residing farther away from the job center end up searching less for a job and are less likely to be employed because they tend to interact less with other workers. This is because it is more costly to socially interact with other workers the farther away a worker lives from the CBD.

We then consider the case of two populations, say the majority and the minority group. We analyze two types of equilibria that can be characterized as follows. In the first equilibrium, the majority group chooses to live close to the job center while the minority group prefers to reside far away from it. This is the European equilibrium, which is typical of European cities (such as Paris, London, Rome, Stockholm, etc.) where ethnic minorities tend to reside in the suburbs far away from jobs while the white majority group tend to live close to the CBD. ${ }^{1}$ In the second equilibrium, the opposite occurs so that the minority group resides close to the CBD while the majority group live at the outskirts of the city. This is the American equilibrium, which is typical of American cities (such as Los Angeles, Atlanta, Houston, etc.) where ethnic minorities (blacks and Hispanics) tend to reside close to the CBD while the white majority group tend to live at the periphery of the city. $^{2}$ In the European equilibrium, ethnic minorities face both geographical segregation or spatial mismatch because they are physically separated from jobs and racial segregation or racial mismatch because they are separated from white workers and do not benefit from their social networks. In the American equilibrium, ethnic minorities "only" face racial segregation since they reside close to jobs.

We show that the majority group experiences a lower unemployment rate than the minority

\footnotetext{
${ }^{1}$ See e.g. Fieldhouse (1999), Åslund et al. (2010), Gobillon et al. (2011), Boeri et al. (2015).

${ }^{2}$ See e.g. Cutler and Glaeser (1997), Borjas (1998), Ross (1998), Cutler et al. (1999), Card and Rothstein (2007), Glaeser et al. (2008), Hellerstein et al. (2008).
} 
group in any of these equilibria. This is one of our key results, which shows that, even if the majority population (i.e. the white population) resides far away from jobs, they can still experience a higher employment rate than the minority population (i.e. the black population) who resides closer to jobs as long as the population size of the majority group is large enough. In our model, this is because there is a trade off between residing far way from jobs, which implies higher costs of interacting with peers and thus lower search activities, and a large population size, which increases the network-size effects and thus increases search activities. In other words, whites can compensate their disadvantage in terms of location because of a bigger population, which gives them access to a larger network, inducing them to search more intensively for jobs than black workers, leading, in turn, to a better-quality network (i.e. more employed workers in the majority social network). This is not the case for ethnic minorities when they reside far away from the CBD since their network cannot compensate for their location disadvantage.

This result is quite unique as it can explain the low employment rates of ethnic minorities both in European and American cities. As stated above, the main reason for this result is the fact that the social network of the white majority group is large and of high-quality while the opposite is true for the etnic-minority network. We believe that this is the first theoretical model that can explain both the European and the American situations of minority workers in an unified framework.

We then extend our model in two different directions. First, we allow workers from one group to socially interact with workers from the other group. We show under which conditions there exist spatial equilibria for which the two groups choose not to interact with each other. In other words, we show how racial segregation endogeneously emerges in equilibrium. Second, we allow workers to direct their search so that they can decide with whom they want to socially interact more. We show that, under some conditions, the majority group still experiences a lower unemployment rate, even when they reside far away from jobs. Indeed, even though the two populations are identical in terms of characteristics and no group experiences any discrimination, we can demonstrate under which conditions ethnic minorities always experience higher unemployment rates, socially interact only with people from their own group and social interact less with them compared to the majority group.

The paper unfolds as follows. The next section highlights our contribution with respect to the literature. Section 3 presents the benchmark model where we determine the employment rate, workers' search activities and location decisions. Section 4 discusses the urban equilibrium for an homogenous population. Section 5 analyzes the urban equilibria with two populations. Section 6 extends the analysis to the case when workers choose the intensity of ties to each member of their own population (directed search). Finally, Section 7 concludes. All proofs of the propositions can be found in the Appendix at the end of the paper. 


\section{Related literature}

Our paper contributes to the literature on "social interactions and cities", which is a small but growing field.

Urban economics and economics of agglomeration There is an important literature in urban economics looking at how interactions between agents create agglomeration and city centers. ${ }^{3}$ It is usually assumed that the level of the externality that is available to a particular firm or worker depends on its location relative to the source of the external effect - the spillover is assumed to attenuate with distance - and on the spatial arrangement of economic activity. This literature (whose keystones include Beckmann, 1976; Fujita and Ogawa, 1980; and Lucas and Rossi-Hansberg, 2002; Helsley and Strange, 2014; Behrens et al., 2015) examines how such spatial externalities influence the location of firms and households, urban density patterns, and productivity. For example, Glaeser (1999) develops a model in which random contacts influence skill acquisition, while Helsley and Strange (2004) consider a model in which randomly matched agents choose whether and how to exchange knowledge. Similarly, Berliant et al. (2002) show the emergence of a unique centre in the case of production externalities while Berliant and Wang (2008) demonstrate that asymmetric urban structures with centres and subcenters of different sizes can emerge in equilibrium. More recently, Mossay and Picard (2011, 2013) propose interesting models in which each agent visits other agents so as to benefit from face-to-face communication (social interactions) and each trip involves a cost which is proportional to distance. These models provide an interesting discussion of spatial issues in terms of use of residential space and formation of neighborhoods and show under which condition different types of city structure emerge. All these models are different from ours since the labor market is not explicitly modeled and therefore the impact of social interactions on the labor-market outcomes is not analyzed.

Peer effects, social networks and urbanization There is a growing interest in theoretical models of peer effects and social networks (see e.g. Akerlof, 1997; Glaeser et al., 1996; Ballester et al., 2006; Calvó-Armengol et al., 2009; Jackson, 2008; Jackson and Zenou, 2015). However, there are very few papers that explicitly consider the interaction between the social and the geographical space. ${ }^{4}$ Brueckner et al. (2002), Helsley and Strange (2007), Brueckner and Largey (2008), Zenou (2013) and Helsley and Zenou (2014) are exceptions but, in all these models either the labor market is not included or social interactions are exogenous. Sato and Zenou (2015) is the only paper that has both aspects but the focus is totally different since it mainly analyzes on the role of

\footnotetext{
${ }^{3}$ See Fujita and Thisse (2013) for a literature review.

${ }^{4}$ Recent empirical researches have shown that the link between these two spaces is quite strong, especially within community groups (see e.g. Topa, 2001; Bayer et al., 2008; Ioannides and Topa, 2010; Hellerstein et al., 2011; Patacchini and Zenou, 2012; Del Bello et al., 2015). See also Ioannides (2012, Chap. 5), Ross (2012) and Topa and Zenou (2015) who review the literature on social interactions and urban economics.
} 
weak and strong ties in the labor market and explains why, in denser areas, individuals choose to interact with more people and meet more random encounters (weak ties) than in sparsely populated areas. Finally, Schelling (1971) is clearly a seminal reference when discussing social preferences and location. Shelling's model shows that, even a mild preference for interacting with people from the same community can lead to large differences in terms of location decision. Indeed, his results suggest that total segregation persists even if most of the population is tolerant about heterogeneous neighborhood composition. ${ }^{5}$ Our model is very different from models a la Schelling since we focus on the interaction between the labor market and social interactions.

To the best of our knowledge, our paper is the first one to provide a model that shows how the urban spatial structure of a city affects both social interactions and the labor-market outcomes of workers.

Spatial mismatch There is ample evidence showing that distance to jobs is harmful to workers, in particular, ethnic minorities. This is known as the "spatial mismatch hypothesis". Indeed, first formulated by Kain (1968), the spatial mismatch hypothesis states that, residing in urban segregated areas distant from and poorly connected to major centres of employment growth, black workers face strong geographic barriers to finding and keeping well-paid jobs. There are, however, very few theoretical models explaining these stylized facts (for a survey see Gobillon et al. 2007, and Zenou, 2009). The standard approach is to use a search model to show that distant workers tend to search less (due to lack of information about jobs or less opportunities to find a job) and thus stay longer unemployed (Coulson et al., 2001; Wasmer and Zenou, 2002). ${ }^{6}$ The only paper that explains the spatial mismatch of the minority workers uses a social-interaction approach is that of Zenou (2013). He shows that if workers only find jobs through weak and strong ties (social networks), then minority workers may experience adverse labor outcomes because, by living far away from jobs, they will mainly interact with other minority workers who are themselves more likely to be unemployed. In this literature, all models have to assume some discrimination against minority workers (usually in the housing market) to obtain the different outcomes for minority and majority workers.

Our main contribution to this literature is twofold. First, we propose a model where, without any form of discrimination in the labor and housing markets, segregation in the urban and social space arises endogenously in equilibrium. Second, we are able to explain why ex ante identical workers can end up with very different labor-market outcomes and different locations in the city. In particular, we are able to show that whether ethnic minorities reside close to jobs (as in American

\footnotetext{
${ }^{5}$ This framework has been modified and extended in different directions, exploring, in particular, the stability and robustness of this extreme outcome (see, for example, Zhang, 2004 or Grauwin et al., 2012).

${ }^{6}$ See also Brueckner and Zenou (2003) for a model of spatial mismatch but without an explicit search model. In an efficiency wage model where, in equilibrium, no worker shirks, they show that housing discrimination can lead to adverse labor-market outcomes for black workers.
} 
cities) or far away from jobs (as in European cities), they always experience a higher unemployment rate than the white majority group because of smaller and worse-quality networks.

\section{The benchmark model}

\subsection{Employment}

We assume a linear city with unit width, two working populations of exogenous size $P_{i}$ each, and a geographical support (set) $D_{i} \subset \mathbb{R}, i=1,2$, for these two populations. All workers (belonging to population 1 or 2 ) work in the Central Business District (CBD), located at $x=0$. The workers of these two populations have exactly the same characteristics: they have the same productivity, the same wage $w,{ }^{7}$ the same unit use of residential space and the same linear commuting costs $t$ (per unit of distance) to commute to the CBD.

Each individual of type $i$ (i.e. belonging to population $i=1,2$ ) located at a distance $x$ from the $\mathrm{CBD}$ can have social interactions with the members of her own population and decides with how often she wants to interact with them. Each social interaction implies a travel cost $\tau$ (per unit of distance) and allows the individual to acquire a piece of job information. ${ }^{8}$ Individuals only interact with individuals from the same population because of cultural differences and/or language barriers. There is also strong evidence that ethnic minorities use extensively their social networks in finding a job (Battu et al., 2011) and that the majority and minority groups, for example blacks and whites in the United States, do not interact much with each other (Sigelman et al., 1996; Topa, 2001). For example, in 1995, to the question: "What race are your close friends?", 87 percent of whites and 76 percent of blacks answered either "mostly my race", or "almost all my race", or "all my race" (Tuch et al., 1999). Using data of students in US schools, both Quillian and Campbell (2003) and Patacchini and Zenou (2015) found that blacks are less likely to have white friends, especially in more segregated neighborhoods and schools. Also, using data from Toronto, Fong and Isajiw (2000) found that low-income minority workers are less likely to develop friendship ties with the majority group. Another way to justify this assumption is that, even at the same skill level, blacks and whites (in the US) typically do not compete for the same jobs, so that their labor markets tend to be separated (or segmented). Indeed, evidence suggests that blacks are much likely to be employed at some types of firms than at others (Holzer and Reaser, 2000). ${ }^{9}$ In Section 5.4 below,

\footnotetext{
${ }^{7}$ In the presence of an unemployment benefit $B$, the wage $w$ should be replaced by $w-B$, i.e. the gain over the unemployment benefit. For simplicity, we normalize $B$ so that $B=0$.

${ }^{8}$ There is strong evidence that many jobs are found through social interactions and networks. See, in particular, Calvó-Armengol and Jackson (2004), Ioannides and Loury (2004), Galenianos (2014) and Zenou (2015).

${ }^{9}$ For instance, federal contractors are more likely to employ blacks than are non-contractors (Leonard, 1990); larger firms are more likely to employ blacks than small firms (Holzer, 1998); and firms having more black customers are more likely to employ blacks than others (Holzer and Ihlanfeldt, 1998). Also, the employment of blacks in manufacturing has declined dramatically in the recent years and recent evidence suggests that most low-educated
} 
we will relax this assumption and discuss realistic conditions under which individuals optimally choose not to interact with people from the other group.

In this paper, we assume that social interactions are the main channel for finding employment. ${ }^{10}$ As in Zenou (2006, 2009), we also assume perfect capital markets with a zero interest rate. ${ }^{11}$ As a result, workers engage in income smoothing as they cycle in and out of unemployment. Thus, workers save while employed and draw down their savings when out of work, with their consumption expenditure reflecting average income. This means that all workers have identical disposable incomes, equal to the average income over the job cycle. As a result, individuals choose their residence given their expected income and utility. This fits the recent US labor market with low long term unemployment. It also fits the case where moving costs are important so that workers are unlikely to change location during their unemployment spells. In this context, the expected utility of an individual of type $i$ (i.e. belonging to population $i=1,2$ ) residing at location $x$ is given by:

$$
U_{i}(x)=e_{i}(x)(w-t|x|)-C_{i}(x)-R(x)
$$

where $e_{i}(x)$ is the individual's employment probability, $C_{i}(x)$ is the total travel cost at a distance $x$ due to social interactions (which will be determined below) and $R(x)$ is the land rent at a distance $x$ from the CBD. In this expression, all workers from the same group, employed and unemployed, socially interact with each other. Given the unit city width and the individuals' unit use of residential space, the total number of workers for each population $i$ is given by $P_{i}=$ $\int_{D_{i}} \lambda_{i}(y) \mathrm{d} y$ where $\lambda_{i}(y)$ denotes the number of individuals at location $y$. The employment for population $i$ is equal to:

$$
E_{i}=\int_{D_{i}} \lambda_{i}(y) e_{i}(y) \mathrm{d} y
$$

while the number of unemployed workers is simply:

$$
\int_{D_{i}} \lambda_{i}(y)\left[1-e_{i}(y)\right] \mathrm{d} y=P_{i}-E_{i}
$$

blacks work in services, like e.g. business and consumer services (Bound and Holzer, 1993). Another way to justify the fact that blacks and whites do not compete for the same jobs is that unskilled jobs are usually performed in teams. Thus, employers prefer to have teams composed of either blacks or whites but not mixed. Finally, it has also been argued that blacks and whites do not specialise in the same type of jobs because of cultural differences (Wilson, 1996).

${ }^{10}$ There is strong evidence that firms mainly rely on referral recruitment (Bartram et al. 1995; Barber et al., 1999; Mencken and Winfield, 1998; Pellizzari, 2010) and it is even common and encouraged strategy for firms to pay bonuses to employees who refer candidates who are successfully recruited to the firm (Berthiaume and Parsons, 2006). It is also well documented that workers use a lot their social networks to find a job (Holzer, 1987, 1988; Ioannides and Loury, 2004).

${ }^{11}$ When there is a zero interest rate, workers have no intrinsic preference for the present so that they only care about the fraction of time they spend employed and unemployed. Therefore, the expected utilities are not state dependent. 
Workers are either employed or unemployed. When working, they may lose their job with an exogenous probability $\beta$ (firm bankruptcy, restructuring, etc.). When they are unemployed, workers residing at location $x$ search for a job with a success probability of $\pi_{i}(x)$. In a steady-state equilibrium, flows in and out unemployment must be equal so that $\beta e_{i}(x)=\pi_{i}(x)\left[1-e_{i}(x)\right]$. This yields the following employment rate:

$$
e_{i}(x)=\frac{\pi_{i}(x)}{\pi_{i}(x)+\beta}
$$

In this paper, we focus on the relationship between social interactions and employment. The benefits of social interactions are through the information flows workers obtain about employment opportunities. We assume that each social interaction with an employed individual is associated to a probability of finding a job in the CBD.

We initially assume that individuals choose the number of interactions entertained with their own population mates whom they randomly meet (random search). Specifically, each individual of type $i$ residing at $x$ chooses to meet $n_{i}(x)$ persons from her own population to socially interact with them. This set-up has both deterministic and probabilistic interpretations about the individuals' social networks. Firstly, we can consider that each individual meets $n_{i}(x)$ times all her population mates in a deterministic way during the period considered in the model. In this case, the model discusses the social interactions during the individual's life time in the city. Secondly, we can consider that each individual chooses her residence location and then build up a permanent social network of random ties after her arrival in the city. Finally, we can interpret this set-up as a repetition of time periods where each individual meet $n_{i}(x)$ different individuals whose identities are randomly drawn within her population in the city. In that case, $n_{i}(x)$ is the expected number of people individuals of type $i$ meet over their lifetime. In all these interpretations, $n_{i}(x)$ corresponds to the concept of weak ties introduced by Granovetter (1973) in which weak ties are generated through professional meetings, casual acquaintances, encounters in sport events, etc. The important part of the assumption of random search is that individuals do not choose their frequency of interaction according to the residential location of their interaction partners. This assumption is made for analytical tractability and is relaxed in Section 6.

Given the employment rate for workers of type $i, E_{i} / P_{i}$, the individual probability of finding a job for a worker of type $i$ residing at $x$ is equal to:

$$
\pi_{i}(x)=\alpha_{i} n_{i}(x) \frac{E_{i}}{P_{i}}
$$

where $\alpha_{i} \equiv \alpha\left(P_{i}\right)$ is an increasing function of $P_{i}$ (i.e. $\alpha\left(P_{i}\right)>0, \alpha^{\prime}\left(P_{i}\right) \geq 0$ ) and captures the population size or network size effect of employment. Indeed, as discussed in Granovetter (1973), larger population size permits stronger diversity in professional activities and therefore improve job information and the likelihood of finding a job. When there are no network size effects, then $\alpha_{i}=\alpha>0$ and is just a positive constant. Equation (3) captures the fact that each individual $i$ located at $x$ chooses to meet a number $n_{i}(x)$ of workers from her own population but only those 
who are employed provide some information about jobs. This equation highlights the random search process since the probability of employment of each person met by worker $i$ is just $E_{i} / P_{i}$ (the aggregate employment rate for workers of type $i$ ) and is not specific to the person met. Quite naturally, the individual's probability of finding a job increases with the number of social interactions $n_{i}(x)$ and with higher employment rate from own population. Finally, observe that the effect of population size $P_{i}$ on $\pi_{i}(x)$, the individual probability of finding a job, is ambiguous. On the one hand, increasing $P_{i}$ reduces the employment rate for workers of type $i, E_{i} / P_{i}$, because there is more competition for job information, which has a negative effect on $\pi_{i}(x)$. On the other hand, increasing $P_{i}$ raises $\alpha_{i} \equiv \alpha\left(P_{i}\right)$ because workers of type $i$ have access to a larger network and thus more information about jobs. This has a positive effect on $\pi_{i}(x)$. As a result, for a given $n_{i}(x)$, equation (3) captures the trade off face by workers of type $i$ in finding a job between more competition and larger network size.

To sum up, equation (3) captures different aspects of social networks. At the intensive margin, $n_{i}(x)$ determines the intensity of social interactions between individuals from the same population $i$ residing at different locations $x$ in the city. At the extensive margin, $\alpha\left(P_{i}\right)$ and $E_{i} / P_{i}$ respectively capture the quantity and the quality of the social network in finding a job. The quantity effect implies that individuals from a greater population will have a larger network size, which increases their chance of finding a job since they meet more people. However, even if a group has a large network but its quality is low, i.e. $E_{i} / P_{i}$ is small, then she will meet many people but few of them will be able to help her find a job since only employed people can give information about a job. As a result, the quality of the network also matters in finding a job.

From (2), we can see that $e_{i}(x)=\pi_{i}(x) /\left[\pi_{i}(x)+\beta\right]$ or equivalently $\pi_{i}(x)=\beta e_{i}(x) /\left[1-e_{i}(x)\right]$. Plugging this value of $\pi_{i}(x)$ into (3), we obtain:

$$
e_{i}(x)=\frac{\alpha_{i} n_{i}(x) E_{i} / P_{i}}{\beta+\alpha_{i} n_{i}(x) E_{i} / P_{i}}
$$

or equivalently

$$
e_{i}(x)=f\left(\alpha_{i} n_{i}(x) E_{i} / P_{i}\right)
$$

where

$$
f\left(z_{i}\right) \equiv \frac{z_{i}}{\beta+z_{i}}
$$

with $f^{\prime}\left(z_{i}\right)>0>f^{\prime \prime}\left(z_{i}\right), f(0)=0$ and $\lim _{z_{i} \rightarrow+\infty} f\left(z_{i}\right)=1$ and where $z_{i} \equiv \alpha_{i} n_{i}(x) E_{i} / P_{i}$.

Indeed, for a given location $x$, higher social contacts and/or higher employment rate in own population raises own probability of finding a job. In this case, the steady-state aggregate employment rate in population $i$ is given by

$$
E_{i}=\int_{D_{i}} e_{i}(x) \mathrm{d} x=\int_{D_{i}} f_{i}\left(\alpha_{i} n_{i}(x) E_{i} / P_{i}\right) \mathrm{d} x
$$




\subsection{Search and social interactions}

Since social interactions occurs at the residence place of the potential information holder, the cost of these social interactions for a worker of type $i$ residing at $x$ is equal to $C_{i}(x)=n_{i}(x) c_{i}(x)$, where $n_{i}(x)$ is her chosen number of interactions and

$$
c_{i}(x)=\frac{1}{P_{i}} \int_{D_{i}} \tau|x-y| \lambda_{i}(y) \mathrm{d} y
$$

measures the average cost of a single social interaction where $\lambda_{i}(y)$ denotes the number of individuals at location $y{ }^{12}$ As a result, each worker $i$ residing at $x$ socially interacts with all members of her own population and each of these interactions implies a commuting cost of $\tau$ per unit of distance. Observe that the location $x$ of a worker $i$ is crucial to determine $c_{i}(x)$. If, for example, a worker $i$ lives close to the CBD, then her $\operatorname{cost} c_{i}(x)$ will be relatively low since this worker will be at the same distance from the left and the right of $x$. But, if this worker is located at one end of the city, then $c_{i}(x)$ will be higher because she must travel longer distances to meet her peers.

In the land market, as it is usually assumed (Zenou, 2009; Fujita and Thisse, 2013), land is offered to the highest bidders. Let $u_{i}$ be the equilibrium (expected) utility obtained by an individual of type $i$. It should be clear that, in equilibrium, all individuals of type $i$ should have the same expected utility $u_{i}$. From (1), it is easily verified that the bid rent of a worker $i$ located at $x$ is given by:

$$
\Psi_{i}\left(x, u_{i}\right)=e_{i}(x)(w-t|x|)-n_{i}(x) c_{i}(x)-u_{i}
$$

where $e_{i}(x)$ and $c_{i}(x)$ are given by (5) and (7). We assume that $w-t|x|>0, \forall x \in[0, b]$ so that workers always have incentives to search for a job.

The number of social interactions $n_{i}(x)$ is a choice variable. Thus, a worker $i$ located at $x$ chooses $n_{i}(x)$ that maximizes her expected utility (1) or equivalently her bid rent (8), i.e.

$$
\Psi_{i}\left(x, u_{i}\right)=\max _{n_{i}(x)}\left[e_{i}(x)(w-t|x|)-n_{i}(x) c_{i}(x)\right]-u_{i}
$$

where $e_{i}(x)$ is given by (5). The first-order condition is equal to: ${ }^{13}$

$$
\alpha_{i}\left(E_{i} / P_{i}\right) f^{\prime}\left(\alpha_{i} n_{i}^{*}(x) E_{i} / P_{i}\right)=\frac{c_{i}(x)}{w-t|x|}
$$

which solves for $n_{i}^{*}(x)$. When deciding the optimal level of social interactions, an individual $i$ located at $x$ trades off the benefits of an increase in $n_{i}(x)$, which raises her chance of obtaining a job (i.e. $\frac{\partial e_{i}(x)}{\partial n_{i}(x)}>0$ ), with its costs since more social interactions imply more travelling and thus higher $c_{i}(x)$. Furthermore, since $f^{\prime}($.$) is a decreasing function, n_{i}^{*}(x)$, the optimal number of interactions in population $i$, increases with the benefits of being employed, i.e. $w-t|x|$. Finally,

\footnotetext{
${ }^{12}$ It measures the expected cost of a single interaction under the probabilistic interpretation of the model.

${ }^{13}$ Given the concavity of $f($.$) , there is a unique maximum given by n_{i}^{*}(x)$.
} 
observe that $n_{i}^{*}(x)$ decreases with $x$, the distance to the CBD, if and only if the right-hand side (RHS) of (10), i.e. $\frac{c_{i}(x)}{w-t|x|}$, increases in $x$. By (5) the employment probability will then also fall with $x$.

To be more specific, we can use the definition of $f($.$) given in (6), to determine (10). We obtain:$

$$
\left[\beta+\alpha_{i} n_{i}^{*}(x)\left(E_{i} / P_{i}\right)\right]^{2}=\frac{\alpha_{i} \beta(w-t|x|)\left(E_{i} / P_{i}\right)}{c_{i}(x)}
$$

which using (4) can be written as: ${ }^{14}$

$$
\left[1-e_{i}^{*}(x)\right]^{2}=\frac{\beta c_{i}(x)}{\alpha_{i}(w-t|x|)\left(E_{i} / P_{i}\right)}
$$

Equations (11) or (12) are well-defined if the right-hand side of (12) is lower than one. Otherwise, we have a corner solution: $e_{i}^{*}(x)=n_{i}^{*}(x)=0$. In the sequel, we focus on the situation where $e_{i}^{*}(x)>0$ and $n_{i}^{*}(x)>0$ for all locations $x$ in the city. For that, we impose that the right-hand side of (12) to be than one, which is equivalent to:

$$
\frac{\alpha_{i}}{\beta} \frac{E_{i}}{P_{i}}>\max _{x}\left[\frac{c_{i}(x)}{w-t|x|}\right]
$$

We can discuss the basic properties of the employment probability $e^{*}(x)$ and the number of social interactions $n_{i}^{*}(x)$. First, when $c_{i}(x) /(w-t|x|)$ increases in $x$, both the employment probability $e_{i}^{*}(x)$ and the number of interactions $n_{i}^{*}(x)$ fall with the distance from the city center. This occurs for two reasons. On the one hand, as in Zenou and Wasmer (2002), the workers who live further away from the job center have a lower income net of commuting cost, $w-t|x|$, which reduces their incentives to search for a job. On the other hand, when $c_{i}(x)$ rises, workers reside further away from their social networks that are a source of job information. In this case, their job search efforts become more costly and workers have smaller incentives to search for a job.

Also, from (12), given the population size $P_{i}$ and therefore $\alpha_{i} \equiv \alpha\left(P_{i}\right)$, it can be shown that the employment probability $e_{i}^{*}(x)$ increases with higher aggregate employment rate $E_{i} / P_{i}$. As workers have higher chance of obtaining information about job opportunities when the individuals in their own social networks are employed, they have higher incentives to search for a job and ultimately are less likely to stay unemployed. However, the impact of the aggregate employment rate $E_{i} / P_{i}$ on the number of interactions $n_{i}^{*}(x)$ is ambiguous and depends on the shape of the function $f($.$) .$ Indeed, one can show from (11) that the number of interactions $n_{i}(x)$ decreases with $E_{i} / P_{i}$ if and only if

$$
\frac{-z f^{\prime \prime}\left(z_{i}\right)}{f^{\prime}\left(z_{i}\right)}>1
$$

\footnotetext{
${ }^{14}$ Observing that (4) implies that

$$
\alpha_{i} n_{i}(x) \frac{E_{i}}{P_{i}}=\frac{e_{i}(x) \beta}{\left[1-e_{i}(x)\right]}
$$
}


evaluated at $z_{i}=n_{i}(x) E_{i} / P_{i}$. This reflects a substitution effect between social interactions and employment level in the population (see below). In particular, the impact of the employment rate on the number of interactions is not monotonic. It is easily checked that $n_{i}^{*}(x)$ falls with $\alpha_{i} E_{i} / P_{i}$ if and only if

$$
\frac{\alpha_{i} E_{i}}{P_{i}}>4 \beta\left[\frac{c_{i}(x)}{w-t|x|}\right] \Leftrightarrow e_{i}^{*}(x)>\frac{1}{2}
$$

Hence, when the aggregate employment rate is not too low, workers react to an increase in aggregate employment rate by reducing their job searches amongst their social ties. Workers have indeed better chance to find a job and reduce their efforts in entertaining social interactions. This substitution effect is more important for workers who bear low search costs and reside closer to the city center (low $\left.c_{i}(x) /(w-t|x|)\right)$.

Applying the envelop theorem, we finally obtain the following land gradient for $x>0:{ }^{15}$

$$
\Psi_{i}^{\prime}\left(x, u_{i}\right)=-e_{i}^{*}(x) t[\operatorname{sign}(x)]-n_{i}^{*}(x) c_{i}^{\prime}(x)
$$

So far, we have analyzed the properties of the model for any possible urban configuration. We would like now to study the possible urban configurations under such model. We first study the case of a unique and homogenous population.

\section{Urban equilibrium with a homogenous population}

Assume a single homogenous population residing on the city support $D=[-b, b]$ where $b$ is the city border and $x=0$ is the CBD. We can drop the subscript $i$. Let the city border be $b=P / 2$ where $P$ is the population size. Remember that we assume that there is a uniform distribution of workers in the city and that each worker consumes one unit of land. Therefore, in the case of a uniform distribution of an homogenous population $P$ on the interval $[-b, b]$, we have $\lambda_{i}(y)=\lambda(y)=1$. In that case, the total social-interaction cost (7) of an individual residing at $x$ is given by:

$$
c(x)=\frac{\tau}{P}\left(\frac{P^{2}}{4}+x^{2}\right)
$$

Therefore, the ratio

$$
\frac{c(x)}{w-t|x|}=\frac{\tau}{P(w-t|x|)}\left(\frac{P^{2}}{4}+x^{2}\right)
$$

increases as one moves from the city center to the border $b$. By (10) and (11), we can conclude that the optimal number of social interactions $n_{i}^{*}(x)$ and the individual employment probability $\pi^{*}(x)$ and $e^{*}(x)$ falls with distance $x$ from the center.

\footnotetext{
${ }^{15}$ We adopt the following notation:

$$
\Psi_{i}^{\prime}\left(x, u_{i}\right) \equiv \frac{\partial \Psi_{i}\left(x, u_{i}\right)}{\partial x}
$$
}


Proposition 1 Consider a homogenous population where workers chose their intensity of social interactions. Then, in any equilibrium, the employment probability $e(x)$ and the optimal number of social interactions $n(x)$ fall with distance from the city center.

Let us now determine the urban configuration. Observe that we consider a closed city model so that the equilibrium utility $u$ is endogenous while the total population $P$ is exogenous and equal to $P=2 b$.

Definition 1 Given that $c(x)$ is determined by (16), a closed-city competitive spatial equilibrium with an homogenous population is defined by a 5-tuple $\left(R^{*}(x), e^{*}(x), E^{*}, n^{*}(x), u^{*}\right)$ satisfying the following conditions:

(i) Land rent (land-market condition):

$$
R^{*}(x)=\left\{\begin{array}{clc}
\max \left\{\Psi\left(x, u^{*}\right), 0\right\} & \text { for } & -b<x<b \\
\Psi\left(x, u^{*}\right)=0 & \text { for } & x=-b \text { and } x=b \\
0 & \text { for } & x>|b|
\end{array}\right.
$$

where $\Psi\left(x, u^{*}\right)$ is given by (9) without subscript $i$.

(ii) Spatial distribution of employment:

$$
e^{*}(x)=\frac{\alpha n^{*}(x) E^{*} / P}{\beta+\alpha n^{*}(x) E^{*} / P}
$$

(iii) Aggregate employment (labor-market condition):

$$
\frac{E^{*}}{P}=\frac{1}{2 b} \int_{-b}^{b} e^{*}(x) \mathrm{d} x
$$

(iv) Spatial distribution of social interactions:

$$
\left[\beta+\alpha n^{*}(x)(E / P)\right]^{2}=\frac{\alpha \beta(w-t|x|)(E / P)}{c(x)}
$$

where $\alpha \equiv \alpha(P)$.

Because of perfect competition in the land market and continuous land rent, equation (17) says that the land has to be allocated to the highest bidders and that, at the city fringe $x=b$ or $x=-b$, it has to be equal to the price of land outside the city, which we normalize to zero. As explained above, the spatial distribution of employment is determined by a steady-state condition, which is equal to (18). In equilibrium, the aggregate employment rate has to be consistent with the individuals' employment probabilities across the city, so that the total employment is given by 
(19). Finally, the equilibrium level of social interactions is the result of individuals' maximization problem as expressed by (20).

Let us now determine the equilibrium value of all endogenous variables. By (12), we have

$$
e^{*}(x)=1-\sqrt{\frac{\beta c(x)}{\alpha(w-t|x|)\left(E^{*} / P\right)}}
$$

and thus (19) can be written as (noticing that $P=2 b$ ):

$$
\frac{E^{*}}{P}=1-\frac{1}{P} \sqrt{\frac{\beta}{\alpha} \frac{P}{E^{*}}} \int_{-P / 2}^{P / 2} \sqrt{\frac{c(x)}{(w-t|x|)}} \mathrm{d} x
$$

This is the key equilibrium equation that determines $E^{*}$ where $c(x)$ is given by (16). Once we have calculated $E^{*}$, we obtain $n^{*}(x)$ using $(20), e^{*}(x)$ using (18), and finally the utility $u^{*}$ and the land rent $R(x)$ using (17).

As can be seen from (22), in the absence of commuting and search costs $(t=\tau=c(x)=0)$, all workers find automatically a job and $E^{*} / P=1$. The presence of commuting and search costs deter, however, workers to search and take a job. As a result the employment probability is lower. After some algebra, we get the following labor market condition:

$$
\left(1-\frac{E^{*}}{P}\right) \sqrt{\frac{E^{*}}{P}}=\Gamma(P)
$$

where

$$
\Gamma(P) \equiv \sqrt{\frac{\beta}{\alpha(P)}} \frac{1}{P} \int_{-P / 2}^{P / 2} \sqrt{\frac{c(x)}{w-t|x|}} \mathrm{d} x
$$

Note that the LHS of (23) represents the benefits from job search (or social interactions). The LHS of $(23)$ is a bell-shape curve in $E / P$ with a maximum at $E / P=1 / 3$. The RHS of (23), i.e. the function $\Gamma(P)$, reflects the combination of search, commuting costs and the network-size effects. It first includes the average share of commuting and search cost in the employment earnings. Higher commuting and search costs indeed increase $\Gamma(P)$. Network-size effects reduce this effect. Since the only endogenous variable is $E^{*}$, we can depict the equilibrium in Figure 1.

\section{[Insert Figure 1 here]}

We have the following result:

Proposition 2 Consider the equilibrium defined in Definition 1. If $w$ is large enough and

$$
\Gamma(P) \leq 0.384
$$


holds, then there exists a unique equilibrium for which $1 / 3<E^{*} / P<1$. In this equilibrium, the employment rate $E^{*}$ decreases with the commuting cost $t$, the search cost $\tau$ and the job-destruction rate $\beta$ but increases with the wage $w$ and the effectiveness of social interactions in finding a job $\alpha$.

First, observe that condition (25) puts an upper bound on commuting and search costs. Indeed, when network-size effects $\alpha(P)$ are not too strong compared to search and commuting costs, $\Gamma(P)$ is a monotone increasing function so that condition (25) also puts an upper bound $\bar{P} \equiv \Gamma^{-1}(0.384)$ on the city size (where $\Gamma^{-1}$ is the inverse of the function $\Gamma$ ). Too large city sizes imply too much dispersed searches so that workers have no incentive to search and take jobs. By contrast, when network-size effects are large (high $\alpha(P)), \Gamma(P)$ becomes U-shaped. Condition (25) then defines an interval for the equilibrium city size, which is $\left[\bar{P}_{a}, \bar{P}_{b}\right]$ with $\bar{P}_{a}<\bar{P}_{b} \leq w / t$.

Second, we assume that $w$ is large enough to avoid a corner solution for which $E^{*} / P=e^{*}(x)=$ $n^{*}(x)=0$. Third, if the commuting cost $t$ and the search cost $\tau$ are too high, then equilibrium employment $E^{*}$ decreases because it is more costly to be employed (higher $t$ ) and to search for a job (through social interactions $\tau$ ). Since $\alpha \equiv \alpha(P)$ is the effectiveness of searching for a job via social interactions and $\beta$ is the job destruction rate, the ratio $\alpha / \beta$ can be viewed as an indicator of the efficiency of the labor market. When this ratio increases, it becomes easier to find a job and jobs last longer and so employment increases. Finally, when wages $w$ are higher, the value of employment is higher and thus workers search more intensively for a job (by increasing $n^{*}(x)>$ $0)$ and therefore employment increases. Furthermore, a larger network-size effect (larger $\alpha(P)$ ) increases the employment rate $E^{*} / P$.

Observe that the network-size effect $\alpha(P)$ benefits workers at the expense of landlords. Indeed, when the graph of $\alpha(P)$ shifts upwards, the function $\Gamma(P)$ falls so that the aggregate employment $E / P$ increases. This increases the employment probability $e(x)$ and decreases the number of job search interactions $n(x)$ everywhere (assuming $e(x)>1 / 2$ ). So, a rise of $\alpha(P)$ increases the utility of the workers at the city border, and by the same token, the utility of all other workers. Because land rent is equal to its zero opportunity cost at the city border $\left(\Psi\left(x, u^{*}\right)=0\right)$, landlords can only capture the difference of the network-size benefit between the city border workers and the others. It can be seen from (20) and(21) that the differences in interaction frequency and employment probality between city border workers and others decreases with $E / P$. As a result, the utility of workers differ to a lesser extent, land rent differentials shrink and the amplitude of land rents fall too. Landlords therefore lose from more network-size effects.

By contrast, job uncertainty makes workers worse off and can make landlords better off. Indeed, if we take the extreme case when workers cannot lose their job (i.e. $\beta \rightarrow 0$ ), which means that they are certain to be employed and thus do not need to search for job, i.e. $e^{0}(x)=1$ and $n^{0}(x)=0$, where the superscript 0 denotes the case when $\beta \rightarrow 0$. In this case, their bid rents are given by $\Psi^{0}\left(x, u^{0}\right)=(w-t|x|)-u^{0}$. Since, as before, the opportunity cost of land is zero at the city edge, i.e. $\Psi^{0}\left(b, u^{0}\right)=0$, we obtain: $u^{0}=(w-t b)$ and $\Psi^{0}\left(x, u^{o}\right)=-t|b-x|$. By contrast, when $\beta>0$, 
the equilibrium bid rent with job search is given by (see (8)):

$$
\Psi\left(x, u^{*}\right)=e^{*}(x)(w-t|x|)-n^{*}(x) c(x)-u^{*}
$$

where $u^{*}=e(b)(w-t b)-n(b) c(b)$ by the fact that $\Psi\left(b, u^{*}\right)=0$. So the difference in equilibrium utility between the case $\beta \rightarrow 0$ and $\beta>0$ is given by

$$
u^{0}-u^{*}=\left[1-e^{*}(b)\right](w-t b)+n^{*}(b) c(b)
$$

which is strictly positive. Hence, all workers will have a lower utility when $\beta>0$ and the utility difference is proportional to the (un)employment rates and search costs for the workers residing at the city edge. This highlight the role of search frictions in our model. All landlords benefit from higher land rents when workers face job uncertainty (i.e. $\beta>0$ ) if and only if

$$
\Psi^{0}\left(x, u^{0}\right)-\Psi\left(x, u^{*}\right)=\left[\left(1-e^{*}(x)\right)(w-t x)+n^{*}(x) c(x)\right]-\left[\left(1-e^{*}(b)\right)(w-t b)+n^{*}(b) c(b)\right] \leq 0
$$

for all $x>0$. This expresses the fact that the opportunity cost of being unemployed and searching for jobs is lower for workers residing at the center. Plugging the equilibrium values of $e^{*}(x)$ and $n^{*}(x)$ in the above expression, we find that this expression is negative if and only if:

$$
2 \sqrt{\frac{\beta c(x)}{\alpha\left(E^{*} / P\right)}} \sqrt{(w-t x)}-\frac{\beta c(x)}{\alpha\left(E^{*} / P\right)} \leq 2 \sqrt{\frac{\beta c(b)}{\alpha\left(E^{*} / P\right)}} \sqrt{(w-t b)}-\frac{\beta c(b)}{\alpha\left(E^{*} / P\right)}
$$

This inequality holds strictly for large enough $w$ because $c(x)<c(b)$ and $E^{*} / P$ rises and gets close to one when $w$ increases. Let $\widehat{w}$ be the highest root solving both for (26) and (23).

Proposition 3 Larger network-size effects $\alpha(P)$ benefit workers at the expense of landlords. Higher job uncertainty $\beta$ makes all workers worse off but benefit to landlords if $w>\widehat{w}$.

Hence, workers lose twice from job uncertainty $(\beta>0)$. On the one hand, they are worse off because they cannot guarantee their salary and must exert effort to search for new jobs. On the other hand, job search through social interactions increases the utility differential between workers at the city center and at the city edge. As a consequence landlords are able to perform a stronger price discrimination along the urban space. Figure 2 illustrates these results where we display, from the left to the right, the bid rent $\Psi(x, u)$, the employment rate $e$ and the log of $n(x)$, the number of social interactions for each location $x$ in the city. For each plot, we display three curves: a solid one with network-size effects and job uncertainty so that $\beta>0$ and $\alpha \equiv \alpha(P)=\alpha P^{\theta}=\alpha P^{0.2}$, a dashed curve without network-size effects so that $\beta>0$ and $\alpha \equiv \alpha(P)=\alpha P^{0}=\alpha$ and a dotted one without job uncertainty so that $\beta=0$. We can see that all endogenous variables decrease with the distance $x$ to the CBD and that employment is the highest when $\beta=0$ while the land rent is the highest when $\beta>0$ and there are no network-size effects. 


\section{[Insert Figure 2 here]}

Let us now investigate the case of two populations.

\section{Urban equilibrium with two populations}

We now discuss the urban equilibrium when the city hosts two populations. We begin with the case where the two populations are spatially integrated. We then discuss the case where the populations are spatially segregated. We finally discuss the role and the choice of intra-group interactions.

\subsection{Spatial integration}

We first consider an integrated city where the two populations $i=1,2$ reside at every location. As stated above, the two populations have exactly the same characteristics except for the fact that that they do not mix in terms of social interactions and job searches. Each member of population $i$ only meets the members of her own population. We want to show here that the absence of social interactions between populations has no impact on labor outcomes in a spatial equilibrium where the two populations are spatially integrated.

Let the total population with sizes $P_{1}$ and $P_{2}$ with $P_{1}+P_{2}=P$ locate on the intervals $\left[-b_{1}, b_{1}\right]$ and $\left[-b_{2}, b_{2}\right]$. With a uniform distribution, we have: $\lambda_{i}(y)=P_{i} / P$, which is the proportion of individuals $i$ on each plot of land. We consider the symmetric equilibria where each population has a residential density proportional to its constant share $P_{i} / P$ across the city. In this case, the city border is the same for all populations and equal to $b_{i}=b=P / 2, i=1,2$. The cost of search interactions is given by $n_{i}(x) c_{i}(x)$ where

$$
c_{i}(x)=\frac{1}{P_{i}} \int_{-b}^{b} \tau|x-y|\left(\frac{P_{i}}{P}\right) \mathrm{d} y=\frac{1}{P} \int_{-b}^{b} \tau|x-y| \mathrm{d} y
$$

As a result, $c_{i}(x)$ is equal to $c(x)$ and given by (16). For a given population size and city border, the cost of each single interaction is the same whenever the city hosts one population or two integrated populations. "Random" searches imply that workers occur the same expected travel distance since the two populations are equally spread. This stems from the population symmetry in both terms of their characteristics and spatial distributions.

Because $c_{i}(x)=c(x)$, the number of interactions and the employment probability of each worker $\left(n_{i}^{*}(x), e_{i}^{*}(x)\right)$ depends only on the aggregate employment, adjusted for network-size effects, $\alpha_{i} E_{i} / P_{i}$ (see (11) and (12)). It is then clear that this spatial configuration is an equilibrium when

$$
\alpha_{1} E_{1} / P_{1}=\alpha_{2} E_{2} / P_{2}
$$


The number of interactions and employment probability are then identical across populations so that the bid rents $\Psi_{1}(x)$ and $\Psi_{2}(x)$ are also equal for all $x$. No population can offer a higher bid than the other for any piece of land. The equilibrium is defined similarly to Definition 1 . The total employment is then given by

$$
E_{i}=\int_{-b}^{b} f\left[\alpha_{i} n_{i}^{*}(x) E_{i} / P_{i}\right]\left(\frac{P_{i}}{P}\right) \mathrm{d} x
$$

In the absence of network-size effects $\left(\alpha_{1}=\alpha_{2}=\alpha\right)$, the aggregate employment levels are the same across populations and equal to the aggregate employment in the homogenous case. Indeed, condition (27) yields $E_{1} / P_{1}=E_{2} / P_{2}$, which implies that $E_{i} / P_{i}=E / P$ where $E=E_{1}+E_{2}$. In the presence of network-size effects, we get $\left(E_{1} / P_{1}\right) /\left(E_{2} / P_{2}\right)=\left(\alpha_{1} / \alpha_{2}\right)=\alpha\left(P_{1}\right) / \alpha\left(P_{2}\right)$ so that the aggregate employment rate is higher for the larger population. Computing the equilibrium in the same way as for the homogenous case we obtain:

$$
\left(1-\frac{E_{i}^{*}}{P_{i}}\right) \sqrt{\frac{E_{i}^{*}}{P_{i}}}=\frac{\alpha\left(P_{i}\right)}{\alpha(P)} \Gamma(P)
$$

where $\Gamma(P)$ is defined in (24). Therefore, because $\alpha\left(P_{i}\right) \leq \alpha(P)$ and the LHS falls in $E_{i}^{*} / P_{i}$ in equilibrium, the aggregate employment rates are smaller than the one found in the homogenous case. This is because each sub-group benefits from a smaller social network size.

We summarize this result in the following proposition:

Proposition 4 Suppose two identical populations that socially interact only with their own group and are spatially integrated. Then, the equilibrium urban structure and employment probabilities are similar as in the case where there is one homogenous population. When there are no network-size effects, $\alpha_{1}=\alpha_{2}=\alpha$, the employment probabilities of the two populations are exactly the same. When there are network-size effects, $\alpha_{i} \equiv \alpha\left(P_{i}\right)$, then the aggregate employment rates are smaller than in the case of homogenous population and the larger population has the higher employment rate.

It must be noted that the spatially integrated configuration should be seen as a benchmark. Indeed, it is not immune to small perturbations of preferences and technologies. Indeed, this equilibrium would break if population 1 earned slightly higher salaries, needed slightly smaller land plots, had a slightly lower commuting or search cost, etc. Those small perturbations would lead to segregated outcomes.

While the absence of intergroup interactions does not alter the equilibrium employment rates when the populations are spatially integrated, we will show that this is not the case when there is spatial segregation. In that case, different employment outcome may arise. This is what we study now. 


\subsection{Spatial segregation and labor-market outcomes}

Suppose that population 1 resides close to the city center, i.e. in the interval $\left[-b_{1}, b_{1}\right]$, while population 2 resides at the outskirts of the city, i.e. at $\left[-b_{2},-b_{1}\right) \cup\left(b_{1}, b_{2}\right]$, where $b_{1}>0$ and $b_{2}>b_{1}$ are the borders of populations 1 and 2 . The population sizes are now given by $P_{1}=2 b_{1}$ and $P_{2}=2\left(b_{2}-b_{1}\right)$ while the total population size is still equal to $P$. In that case, with a uniform distribution, we have: $\lambda_{1}(y)=1$ and $\lambda_{2}(y)=0$ for $y \in\left[-b_{1}, b_{1}\right]$ while $\lambda_{1}(y)=0$ and $\lambda_{2}(y)=1$ for $y \in\left[-b_{2},-b_{1}\right) \cup\left(b_{1}, b_{2}\right]$.

We want to show under which conditions, this spatial configuration is an equilibrium. First, if population 1 corresponds to the "white" or "majority" population and population 2 to the "ethnic" or "minority" population, then this spatial equilibrium corresponds to a spatial mismatch equilibrium (see our discussion in Section 2 on the spatial-mismatch literature) where the minority workers reside far away from jobs. This is what we also called the European equilibrium since it corresponds to a typical European city such as Paris or London where minority workers live in the suburbs and the majority workers reside close to the CBD. Second, if population 1 corresponds to the "ethnic" or "minority" population and population 2 to the "white" or "majority" population, then this corresponds to the American equilibrium (because most American cities have such a structure) where ethnic minority workers (blacks and Hispanics) reside close to the CBD while white workers live at the outskirts of the city. ${ }^{16}$

In this spatial configuration, the search costs are now given by:

$$
c_{1}(x)=\left\{\begin{array}{ccc}
\frac{\tau}{2 b_{1}}\left(b_{1}^{2}+x^{2}\right) & \text { if } & |x| \leq b_{1} \\
\tau|x| & \text { if } & b_{1}<|x| \leq b_{2}
\end{array}\right.
$$

and

$$
c_{2}(x)=\left\{\begin{array}{ccc}
\frac{\tau}{2}\left(b_{1}+b_{2}\right) & \text { if } & |x| \leq b_{1} \\
\frac{\tau}{2\left(b_{2}-b_{1}\right)}\left(b_{2}^{2}-2 b_{1}|x|+x^{2}\right) & \text { if } & b_{1}<|x| \leq b_{2}
\end{array}\right.
$$

Figure 3 displays these two cost functions. It can be checked that the cost $c_{i}(x)$ for each type of worker $i=1,2$ is a symmetric and convex function of $x$. The search costs increase as workers locate farther away from the city center. Furthermore, $c_{1}(x)<c_{2}(x)$ for all $|x|<b_{2}$ and $c_{1}(x)=c_{2}(x)$ at $|x|=b_{2}=\left(P_{1}+P_{2}\right) / 2$. Also, the ratio of average travel costs $c_{2}(x) / c_{1}(x)$ is a monotonically increasing function of $x$, for $x>0$, and a decreasing function, for $x<0$.

\section{[Insert Figure 3 here]}

As a result, we can readily conclude that the employment probability in each population decreases as workers reside further away from the city center and that population 2 (the minority group) has

\footnotetext{
${ }^{16}$ For example, Hellerstein et al. (2008) report that $58 \%$ of black men and $27 \%$ of white men live in central city areas in the United States. They also report that black men are closer to jobs than white men by using either the ratio jobs/residents or male jobs/male residents.
} 
a disadvantage in terms of access to its own members and thus to find a job. This is mainly because workers of type 2 are spread around in the city while workers of type 1 are concentrated at the vicinity of the city-center and geographically closer from each other. We need to have a definition of the equilibrium similar to Definition 1.

Definition 2 Given that $c_{1}(x)$ and $c_{2}(x)$ are determined by (28) and (29), and $P_{1}=2 b_{1}$ and $P_{2}=2\left(b_{2}-b_{1}\right)$, a closed-city competitive spatial equilibrium with two populations, where population 1 (majority group) resides close to the job center while population 2 (minority group) lives far away from the job center, is defined by a 9-tuple $\left(R^{*}(x), e_{1}^{*}(x), e_{2}^{*}(x), E_{1}^{*}, E_{2}^{*}, n_{1}^{*}(x), n_{2}^{*}(x), u_{1}^{*}, u_{2}^{*}\right)$ satisfying the following conditions:

(i) Land rent (land-rent condition):

$$
R^{*}(x)=\left\{\begin{array}{clc}
\max \left\{\Psi_{1}\left(x, u_{1}^{*}\right), \Psi_{2}\left(x, u_{2}^{*}\right), 0\right\} & \text { for } & -b_{2}<x<b_{2} \\
\Psi_{1}\left(x, u_{1}^{*}\right)=\Psi_{2}\left(x, u_{2}^{*}\right) & \text { for } & x=-b_{1} \text { and } x=b_{1} \\
\Psi_{2}\left(x, u_{2}^{*}\right)=0 & \text { for } & x=-b_{2} \text { and } x=b_{2} \\
0 & \text { for } & |x|>b_{2}
\end{array}\right.
$$

(ii) Spatial distribution of employment for type $i$ workers:

$$
e_{i}^{*}(x)=\frac{\alpha_{i} n_{i}^{*}(x) E_{i}^{*} / P_{i}}{\beta+\alpha_{i} n_{i}^{*}(x) E_{i}^{*} / P_{i}}
$$

(iii) Aggregate employment (labor-market conditions):

$$
\begin{aligned}
& \frac{E_{1}^{*}}{P_{1}}=\frac{2}{P_{1}} \int_{0}^{b_{1}} e_{1}^{*}(x) \mathrm{d} x \\
& \frac{E_{2}^{*}}{P_{2}}=\frac{2}{P_{2}} \int_{b_{1}}^{b_{2}} e_{2}^{*}(x) \mathrm{d} x
\end{aligned}
$$

(iv) Spatial distribution of social interactions for type $i$ workers:

$$
\left[\beta+\alpha_{i} n_{i}^{*}(x)\left(E_{i}^{*} / P_{i}\right)\right]^{2}=\frac{\alpha_{i} \beta(w-t|x|)\left(E_{i}^{*} / P_{i}\right)}{c_{i}(x)}
$$

where $\alpha_{i}=\alpha\left(P_{i}\right)$.

The interpretation of the equations are similar to that of Definition 1. As above, we look at equilibria for which $e_{i}^{*}(x)>0$ and $n_{i}^{*}(x)>0$ for all locations in the city. To guarantee that this is always true, we impose that

$$
\left(E_{i} / P_{i}\right)\left(\alpha_{i} / \beta\right)>\frac{c_{i}\left(b_{i}\right)}{w-t b_{i}}, \quad i=1,2
$$


To obtain the labor market conditions for each population $i=1,2$, using (12), we can write (32) and (33) as follows (noticing that $b_{1}=P_{1} / 2$ and $b_{2}=\left(P_{1}+P_{2}\right) / 2$ ):

$$
\left(1-\frac{E_{i}^{*}}{P_{i}}\right) \sqrt{\frac{E_{i}^{*}}{P_{i}}}=\Gamma_{i}
$$

where the average share of commuting and search costs are given by

$$
\Gamma_{1}\left(P_{1}\right) \equiv \sqrt{\frac{\beta}{\alpha\left(P_{1}\right)}} \frac{2}{P_{1}} \int_{0}^{P_{1} / 2} \sqrt{\frac{c_{1}(x)}{w-t|x|}} \mathrm{d} x
$$

and

$$
\Gamma_{2}\left(P_{1}, P_{2}\right) \equiv \sqrt{\frac{\beta}{\alpha\left(P_{2}\right)}} \frac{2}{P_{2}} \int_{P_{1} / 2}^{\left(P_{1}+P_{2}\right) / 2} \sqrt{\frac{c_{2}(x)}{w-t|x|}} \mathrm{d} x
$$

We also suppose in the sequel that network-size benefits are smaller than search and commuting costs so that $\Gamma_{1}$ increases in $P_{1}$ and $\Gamma_{2}$ in $P_{2}$.

We have the following result.

Proposition 5 Consider the equilibrium defined in Definition 2. If the wage $w$ is large enough, $P_{2}$ small enough and the following labor-market condition

$$
\max \left\{\Gamma_{1}\left(P_{1}\right), \Gamma_{2}\left(P_{1}, P_{2}\right)\right\}<0.384
$$

holds, then there exists a unique equilibrium for which $1 / 3<E_{1}^{*} / P<1$ and $1 / 3<E_{2}^{*} / P<1$.

Figure 4 illustrates this proposition. Condition (39) is similar to condition (25) for the homogenouspopulation case. The first constraint, $\Gamma_{1}\left(P_{1}\right)<0.384$, puts an upper bound on population 1 , $\bar{P}_{1} \equiv \Gamma_{1}^{-1}(0.384)$, which is the same as for the homogenous population case. The second constraint, $\Gamma_{2}\left(P_{2}\right)<0.384$, puts an upper bound for population $2, \bar{P}_{2}\left(P_{1}\right) \equiv \Gamma_{2}^{-1}\left(P_{1}, 0.384\right) .{ }^{17}$ We also assume that $w$ is large enough so that there is no corner solution for which $e_{i}^{*}(x)=n_{i}(x)=0$ and that $P_{2}$ is small enough so that population 2 can outbid population 1 at the periphery of the city. This is a reasonable assumption since population 2 is the minority group. As a result, these conditions will hold if both populations $P_{1}$ and $P_{2}$ are not too large.

\section{[Insert Figure 4 here]}

To determine the employment rate for each population, let us first consider the case when there are no network-size effects.

Proposition 6 Consider the equilibrium defined in Definition 2 and suppose that there are no network-size effects $\left(\alpha_{1}=\alpha_{2}=\alpha\right)$. Then, the employment rate of population 1 is always higher than

\footnotetext{
${ }^{17}$ Here, $\Gamma_{2}^{-1}$ is the inverse of $\Gamma_{2}\left(P_{1}, P_{2}\right)$ with respect to the second argument.
} 
that of population 2 whatever their relative sizes, i.e. $E_{1} / P_{1}>E_{2} / P_{2}$. Moreover, $E_{2} / P_{2}$ decreases with higher $P_{1}$ and $P_{2}$. In addition, the worker's employment probability $e_{i}(x)$ decreases with $x$, the distance to the city center and abruptly falls at the border $\left|b_{1}\right|$ between the two populations. The number of social interactions $n_{i}(x)$ also decreases with distance from the center but abruptly rises or falls at the border $b$ depending on whether their employment probability is high or low.

Figure 5 (upper panel) depicts the equilibrium employment levels in this equilibrium where population 1 locates at the city center and population 2 at the periphery of the city. We see that population 1 always experiences a higher employment rate than population 2, the reason being that it has a better average access to its social network. As a result, individuals have more incentives to find a job. The employment level falls dramatically at the border between the two populations. Individuals from population 2 have a different social network than that of population 1 and a lower average access to their interaction partners. This is why the employment rate is higher for population 1. Figure 5 (lower panel) displays the equilibrium land rent for the two populations. Even though workers from population 1 experience a higher employment rate, they pay a higher land price to occupy locations close to the job center. As the periphery of the city, they bid less for land and thus workers from population 2 reside in this part of the city and pay lower land rents compared to what is paid at the vicinity of the city-center.

\section{[Insert Figure 5 here]}

Assume now that there are network-size effects so that $\alpha_{1} \equiv \alpha\left(P_{1}\right) \neq \alpha_{2} \equiv \alpha\left(P_{2}\right)$. Then, the employment rate of population 1 is higher than that of population 2 if and only if $\Gamma_{1}\left(P_{1}\right) \leq$ $\Gamma_{2}\left(P_{1}, P_{2}\right)$, or equivalently,

$$
\sqrt{\frac{\alpha\left(P_{1}\right)}{\alpha\left(P_{2}\right)}}>\frac{\frac{1}{P_{1}} \int_{0}^{P_{1} / 2} \sqrt{\frac{c_{1}(x)}{w-t x}} \mathrm{~d} x}{\frac{1}{P_{2}} \int_{P_{1} / 2}^{\left(P_{1}+P_{2}\right) / 2} \sqrt{\frac{c_{2}(x)}{w-t x}} \mathrm{~d} x}
$$

where the right-hand side (RHS) of this inequality is smaller than one and independent of $\tau$. This inequality holds if $P_{1} \geq P_{2}$. Intuitively, the population at the city center benefits from stronger network size effects when it has a larger population. By continuity, this property holds true when this population is slightly lower than the one at the city edges. However, when it is small enough, this population can face a lower employment rate. If (40) holds, then population 1 in the center has always a higher employment rate than population 2 in the suburbs. Figure 6 illustrates the inequality (40).

\section{[Insert Figure 6 here]}

We would like now to show that the contrary holds, i.e. population 1 living in the center can have in fact a lower employment rate than population 2 , which resides in the suburbs. 
Proposition 7 Suppose that there are network-size effects and assume that $\alpha(0)=0$ and $P \alpha^{\prime}(0) / \alpha(P)<$ 0.2177. Then, there exists a population size threshold $\widehat{P}_{1}$ for which population 1 located around the city-center experience a lower aggregate employment than population 2 , which resides at the outskirts of the city, i.e.

$$
E_{1} / P_{1}<E_{2} / P_{2}, \forall P_{1} \in\left(0, \widehat{P}_{1}\right)
$$

This is one of our key results, which shows that, even if the majority population (i.e. the white population) resides far away from jobs, they can still experience a higher employment rate than the minority population (i.e. the black population) who resides closer to jobs as long as their population size is large enough. This is because there is a trade off between residing far way from the CBD where jobs are located, which implies higher costs of interacting with peers and thus lower search activities, and a large population size, which increases the network-size effects and thus increases search activities. In other words, whites can compensate their disadvantage in terms of location because of a bigger population, which gives them access to a larger network size. This is not the case for ethnic minorites when they reside far away from the CBD since they tend to have lower population size.

As stated in the Introduction, in the European equilibrium, ethnic minorities face both geographical segregation or spatial mismatch because they are physically separated from jobs and racial segregation or racial mismatch because they are separated from white workers and do not benefit from their social networks. In the American equilibrium, ethnic minorities "only" face racial segregation since they reside close to jobs. ${ }^{18}$

This result is quite unique as it can explain the low employment rates of ethnic minorities both in European and the American cities. Indeed, in European cities, minority workers tend to reside far away from the CBD, usually in the suburbs (for example, in Paris, London or Stockholm), and have a lower rate of employment than the majority group. Their social network tends to be relatively small and of low-quality. This is what we obtain in Proposition 4 or Proposition 7 when population 2 is the ethnic minority population. In American cities, ethnic minorities (blacks and Hispanics) tend to reside close to the CBD (for example, in Los Angeles) and experience a lower employment rate than the white majority group. Their network is usually relatively small and of low quality. This is what we show in Proposition 7 when population 1 corresponds to the ethnic minority population and when their population size is low enough (in the Proposition when $P_{1}<\widehat{P}_{1}$ ). Importantly, in both cases, minority workers experience higher unemployment rates compared to white workers.

Let us illustrate the latter result showing the relationship between population size and un-

\footnotetext{
${ }^{18}$ In this model, we do not include different transportation modes, which could reduce the "real" distance to jobs. Indeed, in the United States, even if black workers reside close to jobs, they use public transportation to commute, which is often of poor quality (for example, in Los Angeles). In Europe, public transportation is of much better quality and may reduce the time distance between residential location and jobs.
} 
employment rates between black and white individuals in selected American cities. For selected Metropolitan Statistical Areas (MSAs) in the United States, Table 1 provides the percentage of (black or white) individuals in the population in the MSA or PMSA (\% Pop), the percentage of (black or white) male unemployed in the MSA or PMSA (\% Un) and the population of MSA or PMSA.

\begin{tabular}{|c|c|c|c|c|c|}
\hline & \multicolumn{2}{|c|}{ Blacks } & \multicolumn{2}{c|}{ Whites } & \\
\hline & $\%$ Pop & $\%$ Un & $\%$ Pop & $\%$ Un & Population \\
\hline Atlanta, GA MSA & 29 & 8.98 & 63 & 3.09 & $4,112,198$ \\
\hline Baltimore, MD, PMSA & 27 & 11.69 & 67 & 3.05 & $2,552,994$ \\
\hline Chicago, IL PMSA & 19 & 17.27 & 66 & 4.18 & $8,272,768$ \\
\hline Cleveland-Lorain-Elyria, OH, PMSA & 19 & 14.09 & 77 & 4.17 & $2,250,871$ \\
\hline Detroit, MI, PMSA & 23 & 14.89 & 71 & 4.27 & $4,441,551$ \\
\hline Houston, TX, PMSA & 17 & 10.85 & 61 & 4.46 & $4,117,646$ \\
\hline Los Angeles-Long Beach, CA, PMSA & 10 & 15.57 & 49 & 6.64 & $9,519,338$ \\
\hline Miami, FL, PMSA & 20 & 13.44 & 70 & 6.23 & $2,253,362$ \\
\hline New York, NY, PMSA & 25 & 14.63 & 49 & 5.61 & $9,314,235$ \\
\hline Newark, NJ, PMSA & 22 & 13.90 & 66 & 3.96 & $2,032,989$ \\
\hline Oakland, CA, PMSA & 13 & 12.08 & 55 & 3.95 & $2,392,557$ \\
\hline Philadelphia, PA-NJ, PMSA & 20 & 13.93 & 72 & 4.47 & $5,100,931$ \\
\hline Saint Louis, MO-IL, MSA & 18 & 14.21 & 78 & 4.11 & $2,603,607$ \\
\hline Washington, DC-MD-VA-WV, PMSA & 26 & 8.64 & 60 & 2.63 & $4,923,153$ \\
\hline Table Poplation an
\end{tabular}

Table 1: Population and unemployment rates in American MSAs in 2000

Source: Census (2000)

Table 1 confirms that the size of the black population in each selected city is much smaller than that of the white population and that the former experience a higher unemployment rate than the latter. We can also see that whites tend to experience (slightly) higher unemployment rates in cities where they tend to reside further away from jobs. For example, this is true in a city such as Los Angeles, where white families tend to live further away from the CBD than in a city such as New York or Chicago (Glaeser et al., 2008). Of course, this does not provide in any way a test of our model but just gives some evidence on some assumptions and results of the model such as the different population sizes and different unemployment rates.

To illustrate the results of the propositions above, suppose that $\alpha(P)=\alpha_{0} P^{\theta}$ so that $\alpha^{\prime}(P)=$ $\alpha_{0} \theta P^{\theta-1}$ and $\alpha^{\prime}(0)=0$ if $\theta>1$. As a result, Proposition 7 applies for all $\theta>1$ since $P \alpha^{\prime}(0) / \alpha(P)<$ 0.2177 always holds as the left-hand side (LHS) of this inequality is equal to zero.

In Figure 7, which is similar to Figure 2, we depict our results when there are no network-size effects $\left(\alpha(P)=\alpha_{0} P^{0}=\alpha_{0}=0.1\right)$ as in Proposition 6. We can see that individuals from population 
1, who live close to the $\mathrm{CBD}$, experience a higher employment rate at each location than individuals from population 2 , who reside at the periphery of the city, and socially interact more with their peers. This is an illustration of the European city when ethnic minorities (population 2) tend to live at the outskirts of the city and experience higher unemployment rate than the white majority population (population 1) who reside close to the city center.

\section{[Insert Figure 7 here]}

In Figure 8, we introduce network-size effects so that $\theta=1.5$ and $\alpha(P)=0.1 P^{1.5}$. We obtain the results of Proposition 6 where $P_{2}$ is large enough compared to $P_{1}$, i.e. $P_{2} / P_{1}=9$ so that population 2 is nine times higher than population 1. This can explain the American situation in a city such as Los Angeles where individuals from population 1 (blacks and Hispanics) reside close to the city-center (CBD) while the white population (population 2) tend to live at the periphery of the city. We see that the employment rate of the white population is higher at each location than that of the minority population and that, on average, $E_{2} / P_{2}>E_{1} / P_{1}$. We also see that the minority individuals tend to choose to interact more intensively with their peers but on a much smaller area than the whites. This is because there are few minority workers and they all reside close to each other at the vicinity of the CBD. As a result, since the costs of interacting are low, they tend to socially interact a lot with each other but, because the size of their network is quite small, they have less chance to find a job and, as a result, their social network will be of worse quality than that of the white workers.

This result is new and interesting because it highlights the feedback effect of space and segregation on labor-market outcomes. If we take too identical populations in all possible characteristics, then employment differences result from the existence of spatial segregation and the resulting spatial organization of workers' social networks. Workers obtain job information through their social contacts that belong to the same type but organize in a different way through the urban area. This mechanism contrasts with the analysis presented by the literature that assumes some exogenous discrimination by landlords (see e.g. Brueckner and Zenou, 2003 or Zenou, 2013) or by employers (Verdier and Zenou, 2004).

\section{[Insert Figure 8 here $]$}

For the American cities, there is strong evidence on the segregation of black workers, racial homogeneity and disconnection to jobs. Indeed, in 1980, after a century of suburbanization, $72 \%$ of metropolitan blacks lived in central cities, compared to $33 \%$ of metropolitan whites (Boustant, 2010). The racial homogeneity of neighborhoods is a well documented phenomenon in US cities. In 1979, for example, the average black lived in a neighborhood that was $63.6 \%$ black, even though blacks formed only 14.9\% of the population (Borjas, 1998). In the 1990 census, the figures were similar (Cutler et al., 1999). Racial segregation by jurisdiction and neighborhoods has historical roots in two population flows: black migration from the rural South and white relocation from 
central cities to suburban rings. Both flows peaked during World War II and the subsequent decades (Boustant, 2010). As in our model, many studies find that blacks who live in segregated metropolitan areas have lower labor-market outcomes than their counterparts in more integrated areas (for an overview, see Boustant, 2012). This difference appears to reflect the causal effect of racial segregation on economic outcomes. This literature shows that the association between segregated environments and minority disadvantage is driven in part by physical isolation of black neighborhoods from white neighborhoods and in part by harmful social interactions within black neighborhoods, especially due to concentrated poverty.

\subsection{Numerical simulations}

To better illustrate our different equilibria, let us perform some simple numerical simulations.

First, suppose that there no network-size effects so that $\alpha^{\prime}(P)=0$. Let us illustrate Proposition 6 and the conditions for which the equilibrium exists and is unique. We know that, when there no network-size effects, the population residing close to the CBD will always experience a higher employment rate. Table 2 shows the value of each population's aggregate employment rates $E_{1}^{*} / P_{1}$ and $E_{2}^{*} / P_{2}$ with varying population sizes $P_{1}$ and $P_{2}$. For instance, a city with $P_{1}=P_{2}=1$ has aggregate employment rates equal to $E_{1}^{*} / P_{1}=0.94$ and $E_{2}^{*} / P_{2}=0.90$. This table confirms the results of Proposition 6, which states that, when there no network-size effects, whatever its relative size, people from population 1 , who reside close to the job center (majority group) has a higher aggregate employment rate than individuals from population 2, who live far away from the job center (ethnic minority group). This is the European city and confirms the spatial-mismatch hypothesis where distance to jobs has a negative impact of labor-market outcomes. We also see in this table that, $E_{2}^{*} / P_{2}$, the aggregate employment rate of population 2 decreases with its population size $\left(P_{2}\right)$ and with the size of population $1\left(P_{1}\right)$. Note that the table also shows that the city can support an equilibrium for which the peripheral population is larger than the central one (see for instance the configuration where $P_{1}=0.1$ and $P_{2}=30$ ).

Table 2 also confirms Proposition 5 according to which populations cannot be too large to sustain an urban equilibrium (see condition (39)). The "-" signs indicate when the urban equilibrium does not exist because either (36) have no solution or the bid rent condition $\Psi_{2}(x)>\Psi_{1}(x)$ is violated on the interval $\left(b_{1}, b_{2}\right]$. Importantly, the table shows the existence of multiple equilibria for many population configurations. For instance, there exist both an equilibrium with population sizes $\left(P_{1}, P_{2}\right)=(0.1,1)$ and employment rates $\left(E_{1}^{*} / P_{1}, E_{2}^{*} / P_{2}\right)=(0.98,0.94)$ and an equilibrium with $\left(P_{1}, P_{2}\right)=(1,0.1)$ and $\left(E_{1}^{*} / P_{1}, E_{2}^{*} / P_{2}\right)=(0.94,0.92)$. We can see that the total equilibrium employment $E_{1}^{*}+E_{2}^{*}$ is higher in the former than in the latter when the center population has a bigger size. The multiplicity of equilibria also takes place in the configurations where both populations have identical sizes. For example, when $\left(P_{1}, P_{2}\right)=(1,1)$, one population has a employment rate of either 0.94 or 0.9 depending whether it locates at the city center or in the periphery. The 
multiplicity arises because of the convex travel costs incurred for social interactions, which makes bid rents non-linear (see Figure 3).

\begin{tabular}{c|ccccccccc}
\hline \hline & \multicolumn{10}{|c}{$P_{2}$} \\
$P_{1}$ & 0.1 & 0.5 & 1 & 5 & 10 & 15 & 20 & 30 & 40 \\
\hline \hline 0.1 & $(98,97)$ & $(98,95)$ & $(98,94)$ & $(98,86)$ & $(98,79)$ & $(98,73)$ & $(98,68)$ & $(98,56)$ & - \\
0.5 & $(96,95)$ & $(96,93)$ & $(96,92)$ & $(96,85)$ & $(96,78)$ & $(96,73)$ & $(96,67)$ & $(96,55)$ & - \\
1 & $(94,92)$ & $(94,91)$ & $(94,90)$ & $(94,84)$ & $(94,78)$ & $(94,72)$ & $(94,66)$ & $(94,54)$ & - \\
5 & $(86,82)$ & $(86,82)$ & $(86,81)$ & $(86,76)$ & $(86,71)$ & $(86,65)$ & $(86,59)$ & $(86,44)$ & - \\
10 & $(79,73)$ & $(79,73)$ & $(79,72)$ & $(79,68)$ & $(79,62)$ & $(79,56)$ & $(79,48)$ & - & - \\
15 & $(74,64)$ & $(74,64)$ & $(74,63)$ & $(74,59)$ & $(74,52)$ & $(74,42)$ & - & - & - \\
20 & $(68,55)$ & $(68,54)$ & $(68,54)$ & $(68,47)$ & - & - & - & - & - \\
30 & - & - & - & - & - & - & - & - & - \\
\hline \hline
\end{tabular}

Table 2: Equilibrium employment rates (percent) $E_{1}^{*} / P_{1}$ and $E_{2}^{*} / P_{2}$.

Parameters: $t=\tau=\alpha(P)=\beta=0.1$ and $w=10$.

This numerical example also suggests that the multiplicity of equilibria occurs as long as populations are not too large since when $P_{1} \geq 20$ and $P_{2} \geq 20$ no equilibrium can be sustained. Finally, there exist population configurations that support only one equilibrium. For example, the population configuration $\left(P_{1}, P_{2}\right)=(10,20)$ is an equilibrium whereas $\left(P_{1}, P_{2}\right)=(20,10)$ is not. In that case, the larger population splits and locates at the periphery. Such configurations are found close to the limit where the city stops to be an equilibrium.

Suppose now the presence of network effects. Let us replicate the above simulations for $\alpha(P)=$ $0.1 \times P^{3 / 2}$ (as in Figure 2). The results are displayed in Table 3. First, observe that compared to Table 2, the employment rates are higher for populations larger than 1. Second, urban equilibria support larger city sizes. This is because network-size effects increase the search performance in larger cities. Finally, as stated above, population 2 can have larger employment rates even though it resides at the city edge. This occurs for values when $P_{2} / P_{1}$ is sufficiently large, for example, when $\left(P_{1}, P_{2}\right)=(1,5)$. In that case, individuals from population 2 benefit from network-size effects in their job-search behavior, which more than compensate the search cost due to the distance from the CBD and to their peers. As stated above, this corresponds to a typical American city where the majority group resides outside the CBD and has higher employment levels while the (black or Hispanic) minority group reside close to the CBD and has lower employment level. 


\begin{tabular}{c|ccccccccc}
\hline \hline & & & \multicolumn{1}{c}{$P_{2}$} & & & & \\
$P_{1}$ & 0.1 & 0.5 & 1 & 5 & 10 & 15 & 20 & 30 & 40 \\
\hline \hline 0.1 & $(89,82)$ & $(89,92)$ & $(89,94)$ & $(89,96)$ & $(89,97)$ & $(89,97)$ & $(89,97)$ & $(89,97)$ & $(89,98)$ \\
0.5 & - & $(93,88)$ & $(93,92)$ & $(93,96)$ & $(93,97)$ & $(93,97)$ & $(93,97)$ & $(93,97)$ & $(93,98)$ \\
1 & - & $(94,85)$ & $(94,90)$ & $(94,95)$ & $(94,96)$ & $(94,97)$ & $(94,97)$ & $(94,97)$ & $(94,97)$ \\
5 & - & - & - & $(96,94)$ & $(96,95)$ & $(96,96)$ & $(96,97)$ & $(96,97)$ & $(96,97)$ \\
10 & - & - & - & $(97,92)$ & $(97,95)$ & $(97,96)$ & $(97,96)$ & $(97,97)$ & $(97,97)$ \\
15 & - & - & - & $(97,90)$ & $(97,94)$ & $(97,95)$ & $(97,96)$ & $(97,96)$ & $(97,97)$ \\
20 & - & - & - & - & $(97,93)$ & $(97,94)$ & $(97,95)$ & $(97,96)$ & $(97,97)$ \\
30 & - & - & - & - & $(97,91)$ & $(97,93)$ & $(97,94)$ & $(97,95)$ & $(97,96)$ \\
\hline \hline
\end{tabular}

Table 3: Equilibrium employment rates (percent) $E_{1}^{*} / P_{1}$ and $E_{2}^{*} / P_{2}$. Parameters: $t=\tau=\beta=0.1, \alpha(P)=0.1 \times P^{3 / 2}$ and $w=10$.

\subsection{Inter-group interactions}

So far, we have imposed that workers only socially interact within their own population. This was justified by the existing barriers between social networks such as ethnic or language barriers. In this section, we discuss the possibility of inter-group social interactions and show under which conditions workers choose to socially interact exclusively within their own population. In other words, we want to show how and why racial segregation arises in this model.

Assume now that workers from population $i$ choose their numbers of interactions both with their own population $i$ (denoted by $n_{i i}(x)$ ) and with the other population $j$ (denoted by $n_{i j}(x)$ ). As before, the individual's probability of finding a job depends on the number of social interactions and the aggregate employment rate of the visited population. In addition, language and/or ethnic differences create communication and/or trust issues that may yield possible negative biases in the effectiveness of transmitting information on job opportunities. For that, we assume that the probability of finding a job for a worker of type $i$ is now given by:

$$
\pi_{i}(x) \equiv\left[\alpha_{i} n_{i i}(x) \frac{E_{i}}{P_{i}}+\gamma \alpha_{j} n_{i j}(x) \frac{E_{j}}{P_{j}}\right]
$$

where $\gamma \in(0,1)$ is the negative bias in inter-group communication. This plays a role similar to the preference bias discussed in Currarini et al. (2009). The parameter $\gamma$ could also be interpreted as a meeting bias parameter where individuals from a given group tend to meet less people from the other group. This extended model obviously collapses to our benchmark model when $\gamma \rightarrow 0$. The worker's employment probability is still given by (2), i.e. $e_{i}(x)=f\left[\pi_{i}(x)\right] \equiv \pi_{i}(x) /\left[\pi_{i}(x)+\beta\right]$. The bid rent function is still given by the maximal land rent that the worker can afford and can 
now be written as:

$$
\Psi_{i}(x)=\max _{n_{i i}(x), n_{i j}(x)}\left[e_{i}(x)(w-t|x|)-n_{i i}(x) c_{i}(x)-n_{i j}(x) c_{j}(x)\right]-u_{i}
$$

subject to $n_{i i}(x) \geq 0$ and $n_{i j}(x) \geq 0$, where $c_{i}(x)$ and $c_{j}(x)$ are given by (28) and (29). The optimal number of social interactions is determined as follows. First, if $c_{i}(x) /\left(\alpha_{i} E_{i} / P_{i}\right)<$ $c_{j}(x) /\left(\gamma \alpha_{j} E_{j} / P_{j}\right)$, the worker only chooses to interact with her own population so that

$$
\left(\alpha_{i} E_{i} / P_{i}\right) f^{\prime}\left[\alpha_{i} n_{i i}^{*}(x) E_{i} / P_{i}\right]=\frac{c_{i}(x)}{w-t|x|}
$$

and $n_{i j}^{*}(x)=0$. Obviously, this is equal to the optimal number of interactions $n_{i}^{*}(x)$ that is chosen when there are no inter-group interactions and given by (31). Second, if $c_{i}(x) /\left(\alpha_{i} E_{i} / P_{i}\right)>$ $c_{j}(x) /\left(\gamma \alpha_{j} E_{j} / P_{j}\right)$, the worker chooses to interact only with the other population $j$ so that

$$
\left(\gamma \alpha_{j} E_{j} / P_{j}\right) f^{\prime}\left[\alpha_{j} n_{i j}^{*}(x) E_{j} / P_{j}\right]=\frac{c_{j}(x)}{w-t|x|}
$$

and $n_{i i}^{*}(x)=0$. Finally, if $c_{i}(x) /\left(\alpha_{i} E_{i} / P_{i}\right)=c_{j}(x) /\left(\gamma \alpha_{j} E_{j} / P_{j}\right)$, the worker chooses to interact with any mix of the two populations.

To solve this social-interaction choice, we can consider both the spatially-integrated and spatiallysegregated city equilibria from Sections 5.1 and 5.2.

\section{Proposition 8}

(i) Consider the spatially-integrated city described in Definition 1. In this city, workers have no incentives to interact with the other population.

(ii) Consider the spatially-segregated city described in Definition 2. If

$$
\frac{1}{\gamma} \frac{2 P_{1}+P_{2}}{2 P_{1}}>\frac{\alpha_{2} E_{2} / P_{2}}{\alpha_{1} E_{1} / P_{1}}>\gamma \frac{2 P_{1}+P_{2}}{2 P_{1}}
$$

hold, then no workers want to interact with other workers from the other population.

In the spatially-integrated city, the two populations are totally symmetric, in particular in terms of social-interaction costs and employment rates. In the presence of any small positive bias $\gamma$ in the social interactions with the other population, it is clearly optimal not to interact with the other population.

In the spatially-segregated city, where population 1 lives close to jobs and population 2 further away, things are less straightforward. In that case, population 1 will not interact with population 2 if it has a strong employment advantage and/or if population 2 has a strong employment disadvantage, and/or if it benefits from a stronger network-size effects, and/or if the inter-group communication is ineffective. The first inequality in (43), i.e. $\frac{1}{\gamma} \frac{2 P_{1}+P_{2}}{2 P_{1}}>\frac{\alpha_{2} E_{2} / P_{2}}{\alpha_{1} E_{1} / P_{1}}$, gives the condition for which 
this is true. In the absence of network size effects, the condition always holds because the LHS of first inequality in (43) is larger than one while, by Proposition 6, the RHS is lower than one as the equilibrium aggregate employment rate of population 1 is always larger than the one of population $2\left(E_{1} / P_{1}>E_{2} / P_{2}\right)$. This is not that surprising given that the benefit of reaching an individual of population 2 is less effective in terms of acquisition of job information and more costly in terms of travel cost because of its dispersion around the periphery of the city. This property still holds in the presence of network size effects provided that the latter are not too strong (flat $\alpha(P)$ ).

Similarly, population 2 will not interact with population 1 if the former has no strong employment disadvantage and/or if the latter has no strong employment advantage, and/or if the former benefits from strong enough network-size effects, and/or if the inter-group communication is ineffective. This is expressed by the second inequality in (43), i.e. $\frac{\alpha_{2} E_{2} / P_{2}}{\alpha_{1} E_{1} / P_{1}}>\gamma \frac{2 P_{1}+P_{2}}{2 P_{1}}$. Population 2 has no incentive to seek interactions with the other population if the effectiveness of inter-group communication is low enough. Population 2 has a clear benefit of "chasing" population 1 because the latter conveys more job information and spreads over a compact area. The negative bias in inter-group communication is therefore necessary to cut the incentives to interact with population 1. However, in the absence of network-size effects, this bias needs not to be very strong. As an illustration, a $10 \%$-minority population will not interact with a $90 \%$-majority population for any bias $\gamma$ lower than 0.93 when the aggregate employment rates are $94 \%$ and $92 \%$ for populations 1 and 2 (see Table 2 at the entry $\left.\left(P_{1}, P_{2}\right)=(1,0.1)\right)$. Finally, ceteris paribus, the absence of inter-group interactions holds provided that the population occupying the center is relatively large compared to the one at the periphery. This indeed keeps the RHS low enough in the second condition of (43). In this sense, the combination of spatial segregation and absence of inter-group interactions - as we have studied above - is more likely to be consistent with the urban configuration where a minority group locates far away from the job center. ${ }^{19}$

\section{Directed search interactions}

Let us go back to the model where workers only interact with other workers from the same group. In the previous sections, workers chose the frequency of search interactions without knowing the location of the interaction partners (random search). We now consider that search interactions are directed in the sense that workers choose the frequency of interactions according to the location of their interaction partners. We first consider the homogenous-population case and then the heterogenous one. We show that the results under random and directed search are qualitatively similar.

\footnotetext{
${ }^{19}$ For instance, using the population entries of Table 2 , we find that, for any $\gamma \geq 0.3$, population 2 has no incentives to interact with population 1 if it is a minority group $\left(P_{2}<P_{1}\right)$, but do want to interact with population 1 if it is a majority group $\left(P_{2}>P_{1}\right)$.
} 


\subsection{Homogenous population}

Suppose now that a worker located at $x$ in the city support $D=[-b, b]$ chooses the number of interactions $n(x, y)$ with another individual located at $y$. Each interaction with a person located at $y$ gives her a probability of finding a job equal to $\pi(x, y)$, which depends on the repetition of interaction, $n(x, y)$, and the employment likelihood of the person she meets, $e(y)$. That is, we now assume that the probability of finding a job for a worker located at $x$ and meeting a worker located at $y$ is given by:

$$
\pi(x, y)=\alpha v[n(x, y)] e(y)
$$

where $\alpha$ denotes $\alpha(P)>0$ and where $v[z]=1-\exp [-z],{ }^{20}$ which is increasing and concave, with $v(0)=0$. Quite naturally, there are decreasing returns to the number of social interactions. Interestingly, $n(x, y)$ now varies with $y$ because of $e(y)$, which means that the individual located in $x$ may interact very often with a person located in $y$ because her employment $e(y)$ is high and less often with someone residing in $x^{\prime}$ because $e\left(x^{\prime}\right)$ is low. This was not true in the previous section where $n(x)$ was constant and independent of the location of the person visited because of random search. In that case, each location was visited as often as any other one. The probability of finding a job for a worker located at $x$ now depends on the total set of interactions and is given by:

$$
\pi(x)=\int_{D} \pi(x, y) \mathrm{d} y=\int_{D} \alpha v[n(x, y)] e(y) \mathrm{d} y=\int_{D} \alpha(1-\exp [-n(x, y)]) e(y) \mathrm{d} y
$$

Indeed, instead of (3), we define $\pi(x)$ as in (45) so that each contact with a person depends on her location (here $y$ ) and her employment status $(e(y))$. This is why we have an integral over locations $y$ and why $e(y)$ now replaces $E / P$, which did not vary with location. As before, the probability of being employed is equal to $e(x)=\pi(x) /[\pi(x)+\beta]$. For simplicity, we denote $e(x)=g[\pi(x)]$ where $g(z) \equiv z /(z+\beta)$. It is easily verified that $g(z)$ is an increasing and concave function of $z$.

The bid rent is given by the maximal land rent that the worker can afford given her chosen frequency of directed searches:

$$
\Psi(x)=\max _{n(x, \cdot)} e(x)(w-t|x|)-\int_{D} \tau|x-y| n(x, y) \mathrm{d} y-u
$$

where $\tau|x-y|$ is the travel cost for a single search interaction. By maximizing $\Psi(x)$, we obtain the following first order condition:

$$
v^{\prime}\left[n^{*}(x, y)\right]=\frac{1}{\alpha e(y) g^{\prime}[\pi(x)]} \frac{\tau|x-y|}{w-t|x|}
$$

which has a unique solution for $n^{*}$ because $v^{\prime}($.$) is a decreasing function. The frequency of search$ interactions decreases with the distance to the visited individual $|x-y|$ and with the distance $|x|$

\footnotetext{
${ }^{20}$ It will be clear below why we choose an exponential function.
} 
to the workplace while it increases with the employment likelihood $e(y)$ of the visited agents. From a job search perspective, workers prefer to be closer to other employed workers.

Using the property of the exponential function, $v\left[v^{\prime-1}(z)\right]=1-z$ and keeping the definition of average search cost, i.e. $c(x)=\int_{-b}^{b} \tau|x-y| \mathrm{d} y / P$, the probability of finding a job is then equal to: ${ }^{21}$

$$
\pi(x)=\alpha E-\frac{\alpha P}{g^{\prime}[\pi(x)]} \frac{c(x)}{w-t|x|}
$$

where $c(x)$ is given by (16). Observe that there exists very few $v[$.$] functions such that this integral$ has an explicit formulation because $e(y)$ must aggregate adequately. This is why we chose an exponential function for $v$ [.]. Consider the equilibrium defined in Definition 1 but for directed search so that equation (18) is replaced by $e(x)=\pi(x) /[\pi(x)+\beta]$, where $\pi(x)$ is given by (45), equation (20) is replaced by $(47)$ and $n^{*}(x)$ by $n^{*}(x, y)$. We have the following result.

Proposition 9 Consider a closed-city competitive spatial equilibrium with an homogenous population and directed search. Assume that $w$ is large enough. Then, if the population size $P$ belongs to some interval $[\underline{P}, \bar{P}]$, there exists a unique high-employment level $E^{*}$ such that $e^{*}(x)$ is given by:

$$
e^{*}(x)=1-\frac{\beta+\sqrt{\beta^{2}+4 \alpha \beta(\beta+\alpha E) P \frac{\tau\left[(P / 2)^{2}+x^{2}\right]}{w+t x}}}{2(\beta+\alpha E)}
$$

and $E^{*}$ by

$$
2\left(\beta+\alpha E^{*}\right) E^{*}=\left(\beta+2 \alpha E^{*}\right) P-F\left(P, E^{*}\right)
$$

where

$$
F\left(P, E^{*}\right)=2 \int_{0}^{P / 2} \sqrt{\beta^{2}+4 \alpha \beta\left(\beta+\alpha E^{*}\right) P \frac{\tau\left[(P / 2)^{2}+x^{2}\right]}{w+t x}} \mathrm{~d} x
$$

In this equilibrium, the employment probability $\pi(x)$ and the frequency of search interactions $n^{*}(x, y)$ decreases with the distance to the job center while the employment rate $E^{*}$ decreases with larger commuting $t$ and search costs $\tau$ but increases with wages $w$.

First, the employment rate $e^{*}(x)$ decreases with higher distance $x$ to the job center. Accordingly, workers residing away from the center and their own social network have less incentives to search a job and have therefore lower employment rates. Second, suppose that the travel cost parameter $\tau$ is equal to zero. Then, we obtain the standard "frictional" employment and unemployment rates $e^{*}(x)=\alpha E^{*} /\left(\beta+\alpha E^{*}\right)$ and $1-e^{*}(x)=\beta /\left(\beta+\alpha E^{*}\right)$. Those values are constant

${ }^{21}$ Indeed,

$$
\begin{aligned}
\pi(x) & =\int_{D} \alpha v\left[n^{*}(x, y)\right] e(y) \mathrm{d} y=\alpha \int_{D} v\left\{v^{\prime-1}\left[\frac{1}{\alpha e(y) g^{\prime}[\pi(x)]} \frac{\tau|x-y|}{w-t|x|}\right]\right\} e(y) \mathrm{d} y \\
& =\alpha \int_{D}\left\{1-\frac{1}{\alpha e(y) g^{\prime}[\pi(x)]} \frac{\tau|x-y|}{w-t|x|}\right\} e(y) \mathrm{d} y=\alpha E-\frac{\alpha}{g^{\prime}[\pi(x)]} \frac{\tau \int_{D}|x-y| \mathrm{d} y}{w-t|x|}
\end{aligned}
$$

which leads to (48). 
across space because workers reach each other worker at no cost. They are also sensitive to the number of employed workers. Indeed, the probability $\pi(x, y)$ that a worker located at $x$ finds a job by interacting with someone at $y$ is bounded given our assumption on $v(z)<1$. As a result, the probability of finding a job - given all entertained interactions - $\pi(x)$ increases with the number of employed workers that are visited. Intuitively, an increase in urban population improves the potential amount of job information and therefore raises more than proportionally the employment level. Therefore, search frictions have stronger effects in smaller cities where employment probabilities are lower. If the population is too small, there exists not enough job information to induce workers to search for a job and the equilibrium may therefore fail to exist. This is why Proposition 9 requires the population size to be higher than the threshold $\underline{P}$. Finally, the existence of travel cost exacerbates the effect of search frictions. It is represented in the second term of the square root of (49). Unsurprisingly the job search cost raises the frictional unemployment rate.

Even though we can understand the main properties of equation (50), it is difficult to solve it analytically. We thus run some numerical simulations for this equation. Figure 9 plots the locus of (50) in the space $(E, P)$ (see solid curve). As stated in Proposition 9, this figure confirms the conclusions established in the case of random search. First, the city supports only small enough population (i.e. $P<\bar{P}$ ). Second, there exist multiple equilibria as each population size $P$ supports a high and low employment equilibrium. If we focus on the high-employment equilibrium, then it can be seen that, as the population size rises, the employment level $E^{*}$ first increases and then decreases. This is the result of two forces. On the one hand, when the city size is small, an increase in the population raises the employment rate more than proportionally because the frictional unemployment $\beta / \alpha$ becomes a smaller portion of the workforce. On the other hand, when the city size becomes too large, commuting and search travel costs reduce the workers' net income (wages minus travel cost) and therefore their incentives to search for a job.

\section{[Insert Figure 9 here]}

Let us now investigate the case of two populations.

\subsection{Heterogenous populations}

As in Section 5, let us now consider two populations of sizes $P_{1}$ and $P_{2}$ that spread over the supports $D_{1}=\left[-b_{1}, b_{1}\right]$ and $D_{2}=\left[-b_{2},-b_{1}\right) \cup\left(b_{1}, b_{2}\right]$. Our analysis of Section 6.1 holds by substituting the parameters $(P, D)$ and the functions $(n, e, \pi, \gamma, c)$ respectively for $\left(P_{i}, D_{i}\right)$ and $\left(n_{i}, e_{i}, \pi_{i}, \gamma_{i}, c_{i}\right)$, $i=1,2$, where $c_{i}(x)$ are defined by (28) and (29). The employment probability is given by

$$
e_{i}^{*}(x)=1-\frac{\beta+\sqrt{\beta^{2}+4 \alpha_{i} \beta\left(\beta+\alpha_{i} E_{i}^{*}\right) P_{i} \vartheta_{i}(x)}}{2\left(\beta+\alpha_{i} E_{i}^{*}\right)}
$$


where

$$
\vartheta_{i}(x)=\frac{c_{i}(x)}{w-t|x|}
$$

It can be seen that $e_{i}^{*}(x)$ increases when $c_{i}(x)$ decreases with $x$. Therefore, within the same population, the employment rate rises when workers are located closer to the job center. The difference in a worker's employment probability between two populations not only depends on her location but also on the aggregate employment $E_{i}$ and the size of her population $P_{i}$. In equilibrium, as in (50), the labor market condition for each population $i=1,2$ is determined by:

$$
2\left(\beta+\alpha_{i} E_{i}^{*}\right) E_{i}^{*}=\left(\beta+2 \alpha_{i} E_{i}^{*}\right) P_{i}-F_{i}\left(E_{i}^{*}, P_{1}, P_{2}\right)
$$

where

$$
\begin{aligned}
& F_{1}\left(E_{1}^{*}, P_{1}, P_{2}\right)=2 \int_{0}^{P_{1} / 2} \sqrt{\beta^{2}+4 \alpha_{1} \beta\left(\beta+\alpha_{1} E_{1}^{*}\right) P_{1} \vartheta_{1}(x)} \mathrm{d} x \\
& F_{2}\left(E_{2}^{*}, P_{1}, P_{2}\right)=2 \int_{P_{1} / 2}^{\left(P_{1}+P_{2}\right) / 2} \sqrt{\beta^{2}+4 \alpha_{2} \beta\left(\beta+\alpha_{2} E_{2}^{*}\right) P_{2} \vartheta_{2}(x)} \mathrm{d} x
\end{aligned}
$$

Since $c_{1}(x)$ is equal to $c(x)$, it turns out that $F_{1}\left(E_{1}^{*}, P_{1}, P_{2}\right)$ is equal to the function $F\left(E_{1}^{*}, P_{1}\right)$ defined in (51) for a homogenous population. As a result, population 1 has an aggregate employment that only depends on its own size $P_{1}$. In Figure 9, the solid curve displays the locus of labor market equilibria for population 1 in terms of $\left(P_{1}, E_{1}\right)$ in the absence of network size effects $\left(\alpha_{1}=\alpha_{2}=\right.$ cst). This is the same as for the homogenous population. The properties of population 1's labor market condition exactly replicates those of the homogenous population. In particular, the labor market condition is satisfied only for a population size of $P_{1}$, which is smaller than some upper bound $\bar{P}_{1}$ and there exist two equilibria with high and low employment rates. We again focus on the high-level employment rates. Similar, properties obtain in the presence of network size effects.

The equilibrium employment in the peripheral population 2 is determined by condition (53) for $i=2$ using the term $F_{2}\left(E_{2}^{*}, P_{1}, P_{2}\right)$. The dashed curves in Figure 9 represent the loci of those equilibria in $\left(P_{2}, E_{2}\right)$ for several values of $P_{1}$. We obtain the same properties as in the case of random search. For a given $P_{1}$, there exists an upper envelop $\bar{P}_{2}\left(P_{1}\right)$ such that the labor market condition has a solution. As in the case of random search, the labor market condition holds if $P_{1}<\bar{P}_{1}$ and $P_{2}<\bar{P}_{2}\left(P_{1}\right)$. There also exist a lower and higher employment equilibrium, and we focus on the latter. As in the random-search case, the labor market can support equilibria with the larger or the smaller population residing close to the job center. Finally, Figure 9 shows that, if populations 1 and 2 have the same size, population 1 will have a higher aggregate employment rate $E_{i} / P_{i}$ (that is, the ray from the origin $(0,0)$ to the equilibrium point has smaller angle for population 1$)$. This property remains true as long as population 1 is not too large and approaches the threshold level $\bar{P}_{1}$. Figure 9 also shows that there exists a minimum size for the peripheral population 2 . This is because population 2 must benefit from sufficient social interactions to overcome its disadvantage in terms of job search and commuting to the employment center. 
We can then close the model with the same land market conditions defined in (30) for the random-search case where $\Psi\left(x, u_{i}\right)$ is still defined by (46) with the only difference that $n_{i}(x)$ is now replaced by $n_{i}(x, y)$. It can easily been shown $\Psi\left(x, u_{i}\right)$ is a decreasing function of $x$ but it is difficult to show analytically that population 1 outbids population 2 in the interval $\left[-b_{1}, b_{1}\right]$ and that the reverse is true in the intervals $\left[-b_{2}, b_{1}\right]$ and $\left[b_{1}, b_{2}\right]{ }^{22}$ Therefore, the land market equilibrium must be numerically checked for each configuration of population. Figure 10 provides two examples where the land-market conditions do (left panel) and do not hold (right panel). In this figure, using the land market equilibrium conditions, we have plotted the bid-rent function for some population configurations. In the left panel, the bid rents cross only once so that both land and labor market conditions are simultaneously satisfied. In the right panel, the bid rents cross more than once so that the labor market conditions cannot support an urban equilibrium for which population 1 resides close to the job center and population 2 lives at the periphery of the city.

\section{[Insert Figure 10 here]}

Table 4 displays a set of population configurations for which both the labor and land market clear in the absence of network size effects. It can be seen that equilibrium solutions exist only when the population sizes are neither too small nor too large. Also, the equilibrium employment rate for each population decreases with the size of each population or equivalently with the size of the city.

\begin{tabular}{l|l|llllllll}
\hline \hline & & $P_{2}$ & & & & & & & \\
& & 6 & 8 & 12 & 16 & 20 & 24 & 28 & 32 \\
\hline \hline$P_{1}$ & 6 & $(76,58)$ & $(76,71)$ & -- & -- & -- & -- & -- & -- \\
& 12 & $(80,38)$ & $(80,63)$ & $(80,67)$ & $(80,69)$ & $(80,70)$ & -- & -- & -- \\
& 18 & - & $(80,54)$ & $(80,61)$ & $(80,64)$ & $(80,65)$ & $(80,65)$ & $(80,64)$ & -- \\
& 24 & - & - & $(78,53)$ & $(78,57)$ & $(78,59)$ & $(78,60)$ & $(78,59)$ & $(78,59)$ \\
& 30 & - & - & - & $(76,48)$ & $(76,51)$ & $(76,53)$ & $(76,53)$ & $(76,53)$ \\
& 36 & - & - & - & - & - & - & - & $(74,42)$ \\
\hline \hline
\end{tabular}

Table 4: Aggregate employment rates (percent) $E_{1} / P$ and $E_{2} / P_{2}$

A "_" indicates that there is no solution for the labor market conditions.

A " - - " indicates no land market equilibrium.

Parameters: $(\alpha, \beta, t, \tau, w, \alpha(P))=(0.1,0.1,0.1,0.05,20,0.1)$

Finally, we run some simple numerical simulations without (Figures 11 and 12) and with network-size effects (Figure 13) when search is directed and both land and labor market conditions are simultaneously satisfied. Indeed, in Figures 11 and $12, \alpha(P)=0.5 P^{0}=0.5$ so that there

\footnotetext{
${ }^{22}$ See the end of the Appendix where we partly show these results.
} 
are no network effects. In Figure 11, the size of population 1 is higher than that of population 2 (i.e. $P_{1} / P_{2}=1.8$ ) and, quite naturally, people from population 1 , who reside close to the CBD, experience a higher employment rate than individuals from population 2 and outbid them for land around the CBD. Interestingly, the social interaction decisions, $n_{i}(x, y)$ is not anymore as before, i.e. smoothly decreasing with distance from the CBD (see Figure7), but strongly vary with location with a spike at own residential location. Indeed, on can see that individuals meet more often and thus search more intensively around their own location and tend to little interact with individuals residing further away. In other words, when search is directed, social interactions are very localized. This is a well documented empirical fact (see e.g. Rosenthal and Strange, 2003, 2008; Marmaros and Sacerdote, 2006; Argazi and Henderson, 2008; Patacchini et al., 2015). Interestingly, in Figure 12 , we show that, even with no network effects, if search is directed, individuals from population 2 , who live far away from jobs, can experience a higher employment rate that those from population 1 if $P_{2} / P_{2}$ is sufficiently large. In Figure $12, P_{2} / P_{1}=1.8$ and the average employment rate of population 2 is higher than that of population 1, i.e. $E_{2} / P_{2}=0.878>0.798=E_{1} / P_{1}$. Indeed, since the size of population 2 is larger, individuals from this population mostly meet people residing in nearby locations but have a higher area of search than that of population 1. As a result, they tend to socially interact more with their peers, which leads to more search activity, which compensate for their disadvantage in terms of location far away from jobs and from their peers.

\section{[Insert Figures 11 and 12 here]}

When network-size effects are included in Figure 12 so that $\alpha(P)=0.5 P$, then we obtain a result similar to that of Figure 8. Indeed, if the size of population 2, whose individuals reside at the outskirts of the city, is large enough compared to that of population 1 (here $P_{2} / P_{1}=1.8$ ), then they experience a higher employment rate despite residing far away from jobs. Interestingly, for the same parameter values, the employment ratio $\left(E_{2} / P_{2}\right) /\left(E_{1} / P_{1}\right)$ is much higher in Figure 13 than in Figure 12 (1.16 versus 1.10 $)^{23}$ due to the network-size effects, which gives a double advantage of having a larger population size (more social interactions $n(x, y)$ and higher network effects $\alpha(P)$ ).

\section{[Insert Figure 13 here]}

\section{$7 \quad$ Discussion and policy implications}

In this paper, we develop a model where workers both choose their residential location (geographical space) and their social interactions (social space). In equilibrium, we show under which condition one population resides close to the job center while the other population lives far away from it. Even though the two populations are identical in terms of their characteristics, we find that the

\footnotetext{
${ }^{23}$ The employment rate of population 2 increases from 0.878 to 0.923 while that of population 1 stays at 0.798 .
} 
majority group always experiences a lower unemployment rate than the minority group, even when they reside further away from jobs. This is because they benefit from a larger and better-quality network. In the European city case, where ethnic minorities reside far away from the CBD, totally identical workers end up with different labor-market outcomes. This is due to the fact that, because ethnic minorities are far from jobs and are dispersed in the city, they tend to search less actively than the majority group and end up with higher unemployment rate. In the American city case, where minority workers reside close to the $\mathrm{CBD},{ }^{24}$ the two groups are identical in all aspects but the size of their population. We show that still ethnic minority workers experience higher unemployment rate, not because they are far away from jobs or because their network is dispersed but because they interact only with a few people while, the majority group, meet many more people. As a result, in equilibrium, ethnic minorities will search less and will experience a higher unemployment rate than the majority group.

In a first extension, we show that it can be optimal for the majority and the minority groups not to socially interact with each other. In a second extension, we analyze a model where workers can direct their search so that they interact more with workers who are more beneficial for them (in terms of employment) than others. In that case, the results are relatively close to the ones obtained with random search.

To wrap up, our main contribution is to develop a model where the social and geographical spaces are key determinants of workers' labor-market outcomes. Our model puts forward the importance of the direct interactions between people in obtaining a job and why the majoritygroup social network is easier to access and of better quality than the one for the minority group.

Using the results of this paper, we can draw some policy implications that may improve the integration of minority workers in the city and help them find a job. We have shown that the neighborhood and distance to jobs are crucial in understanding labor-market outcomes of ethnic minorities. If geographical and racial segregation (which encompasses both the cases when ethnic minorities are segregated from jobs because they reside far away from the CBD, as in European cities, and when they are segregated from the white group who has a larger and better-quality social network, as in European and American cities) is the main culprit for the adverse labor-market outcomes of minority workers, then, following Boustant (2012), we can divide policy solutions to segregation into three categories: place-based policies, people-based policies, and indirect approaches to the problems of segregation.

\footnotetext{
${ }^{24}$ This is true, in general, for most cities in the United States. However, as showed by Hellerstein et al. (2008), this does not imply that ethnic minorities (blacks and Hispanics) are close to the jobs that match their skills. Since minorities are mostly unskilled and since many unskilled jobs are in the periphery of the city, by residing close to the CBD, they still can be far away for the jobs that correspond to their skills. This issue is not addressed in our paper since we assume that minority and majority groups are indentical in all possible characteristics, including skills. Our results will even be stronger if we assume that the majority group is more skilled than the minority group or if unskilled jobs are located far away from minority workers.
} 
Place-based policies either improve minority (poor) neighborhoods, rendering them more attractive to white and firm entrants, or require white (rich) suburbs to add housing options affordable to lower-income homeowners or renters. ${ }^{25}$ Examples of such policies are the neighborhood regeneration policies. These policies have been implemented in the US and in Europe through the enterprise zone programs (Papke, 1994; Boarnet and Bogart, 1996; Mauer and Ott, 1999; Bondonio and Engberg, 2000; Bondonio and Greenbaum, 2007; Givord et al., 2013; Briant et al., 2015) and the empowerment zone programs (Busso et al., 2013). For example, the enterprise zone policy consists in designating a specific urban (or rural) area, which is depressed, and targeting it for economic development through government-provided subsidies to labor and capital. The aim of the empowerment zone program is to revitalize distressed urban communities and it represents a nexus between social welfare policy and economic development efforts. By implementing these types of policies, one brings jobs to people and thus facilitates the flows of job information in depressed neighborhoods. These policies mainly fight against residential segregation by reducing the geographical distance between residence and jobs for ethnic minorities.

People-based policies assist homeowners or renters directly, through stronger enforcement of fair housing laws, offers of housing vouchers, or improved access to mortgage finance (such as the Community Reinvestment Act of 1977). Examples of such policies are the Moving to Opportunity (MTO) programs (Katz et al., 2001; Rosenbaum and Harris, 2001; Kling et al., 2005), which have only been implemented in the United States. By giving housing assistance (i.e. vouchers and certificates) to low-income families, the MTO programs help them to relocate to better and richer neighborhoods. The results of most MTO programs (in particular for Baltimore, Boston, Chicago, Los Angeles and New York) show a clear improvement of the well-being of participants and better labor market outcomes, especially in terms of labor-market participation (see, in particular, Katz et al., 2001, Kling et al., 2005, Rosenbaum and Harris, 2001). The MTO programs fight against racial segregation by improving the quality of the social network of ethnic minorities because they will be more likely to mix with white residents.

Finally, indirect approaches target the symptoms of residential segregation, rather than the root causes - for example, by improving public transportation to reduce the isolation of black neighborhoods. Investments in public transport can have a substantial impact on the search activities of low-income minority workers and thus, on their unemployment rate. Indeed, if the labor participation for minority workers is affected by poor access to job locations and poor worker mobility, and if public transportation services are designed to effectively link workers with areas of concentrated employment, then increased access to public transit should yield higher levels of employment, in particular for African Americans (Sanchez, 1998, 1999; Blumemberg and Manville, 2004). ${ }^{26}$

\footnotetext{
${ }^{25}$ For recent overviews on place-based policies, see Kline and Moretti (2014) and Neumark and Simpson (2015).

${ }^{26}$ Researchers studying the relationship between transportation and employment find that reliable transportation leads to increased access to job opportunity, higher earnings, and increased employment stability (Blumemberg, 2000; Cervero et al., 2002; Ong, 2002; Holzer and Ihlanfeldt, 1996).
} 
Which policy is the most effective clearly depends on the sense of causality between (racial and residential) segregation and labor-market outcomes. If segregation is the outcome - not the cause - of adverse labor-market outcomes of ethnic minorities, then people-based policies should be implemented. If segregation is the cause, then policies should focus on workers' geographical location, as in the spatial mismatch literature, and place-based and transportation policies should be implemented. This is ultimately an empirical question of causality - whether people who experience high unemployment rate sort themselves to areas with bad access to jobs and poor social networks or people who are segregated spatially end up with high unemployment rates and a low access to social networks. In our model, labor-market outcomes, segregation and social interactions are determined simultaneously and we have highlighted the role of multiplier effects of both the social space and the geographical space on outcomes. In particular, we have seen that residence-based labor market networks can exacerbate the adverse effects of residential and racial segregation on labor-market outcomes for ethnic minorities. As a result, because of the social multipliers that network effects create, the effects of the above-mentioned policies can be amplified, more so in areas with low employment.

\section{References}

[1] Akerlof, G. (1997), "Social distance and social decisions," Econometrica 65, 1005-1027.

[2] Argazi, M. and V. Henderson (2008), "Networking off Madison avenue," Review of Economic Studies 75, 1011-1038.

[3] Åslund, O., Östh, J. and Y. Zenou (2010), "How crucial is distance to jobs for ethnic minorities? Old question - Improved answer," Journal of Economic Geography 10, 389-422.

[4] Ballester, C., Calvó-Armengol, A. and Y. Zenou (2006), "Who's who in networks. Wanted: The key player," Econometrica 74, 1403-1417.

[5] Barber, A.E., Wesson, M.J., Roberson, Q.M. and S.M. Taylor (1999), "A tale of two job markets: Organizational size and its effects on hiring practices and job search behavior," Personnel Psychology 52, 841-867.

[6] Bartram, D., Lindley, P.A., Marshall, L. and J. Foster (1995), "The recruitment and selection of young-people by small businesses," Journal of Occupational Organizational Psychology 68, 339-358.

[7] Battu, H., Seaman, P. and Y. Zenou (2011), "Job contact networks and the ethnic minorities," Labour Economics 18, 48-56. 
[8] Bayer, P., Ross, S.L. and G. Topa (2008), "Place of work and place of residence: Informal hiring networks and labor market outcomes," Journal of Political Economy 116, 1150-1196.

[9] Beckmann, M.J. (1976), "Spatial equilibrium and the dispersed city," In: Y.Y. Papageorgiou (Ed.), Mathematical Land Use Theory, Lexington, MA: Lexington Books, pp. 117-125.

[10] Behrens, K., Duranton, G. and F. Robert-Nicoud (2015), "Productive cities: Sorting, selection, and agglomeration," Journal of Political Economy, forthcoming.

[11] Berliant, M., Peng, S.-K. and P. Wang (2002), "Production externalities and urban configuration," Journal of Economic Theory 104, 275-303.

[12] Berliant, M. and P. Wang (2008), "Urban growth and subcenter formation: A trolley ride from the Staples Center to Disneyland and the Rose Bowl," Journal of Urban Economics 63, 679-693.

[13] Berthiaume, J. and W. Parsons (2006), "Referral bonuses: A popular way to bring in new talent," Society for Human Resource Management, http://moss07.shrm.org/hrdisciplines/compensation/Articles/Pages/CMS_016894.aspx.

[14] Blumemberg, E. (2000), "On the way to work: Welfare recipients and barriers to employment," Economic Development Quarterly 16, 314-325.

[15] Blumemberg, E. and M. Manville (2004), "Beyond the spatial mismatch hypothesis: Welfare recipients and transportation policy," Journal of Planning Literature 19, 182-205.

[16] Boarnet, M.G. and W.T. Bogart (1996), "Enterprise zones and employment: Evidence from New Jersey," Journal of Urban Economics 40, 198-215.

[17] Boeri, T., De Philippis, M., Patacchini, E. and M. Pellizzari (2015), "Immigration, housing discrimination and employment," Economic Journal, forthcoming.

[18] Bondonio, D. and J. Engberg (2000), "Enterprise zones and local employment: Evidence from the states' program," Regional Science and Urban Economics 30, 519-549.

[19] Bondonio, D. and R.T. Greenbaum (2007), "Do local tax incentives affect economic growth? What mean impact miss in the analysis of enterprise zone policies," Regional Science and Urban Economics 37, 121-136.

[20] Borjas, G.J. (1998), "To ghetto or not to ghetto: Ethnicity and residential segregation," Journal of Urban Economics 44, 228-253.

[21] Bound, J. and Holzer, H.J. (1993), "Industrial shifts, skill levels, and the labor market for white and black males," Review of Economics and Statistics 75, 387-395. 
[22] Boustant, L.P. (2010), "Was postwar suburbanization white flight? Evidence from the black migration," Quarterly Journal of Economics 125, 417-443.

[23] Boustant, L.P. (2012), "Racial residential segregation in American cities," In: N. Brooks, K. Donaghy and G.-J. Knaap (Eds.), The Oxford Handbook of Urban Economics and Planning, Oxford: Oxford University Press, pp. 318-339.

[24] Briant, A., Lafourcade, M. and B. Schmutz (2015), "Can tax breaks beat geography? Lessons from the French EZ experience," American Economic Journal: Economic Policy 7, 88-124.

[25] Brueckner, J.K. and A.G. Largey (2008), "Social interaction and urban sprawl," Journal of Urban Economics 64, 18-34.

[26] Brueckner, J.K., Thisse, J-F. and Y. Zenou (2002), "Local labor markets, job matching and urban location," International Economic Review 43, 155-171.

[27] Brueckner, J.K. and Y. Zenou (2003), "Space and unemployment: The labor-market effects of spatial mismatch," Journal of Labor Economics 21, 242-266.

[28] Busso, M., Gregory, J. and P. Kline (2013), "Assessing the incidence and efficiency of a prominent place based policy," American Economic Review 103, 897-947.

[29] Calvó-Armengol, A. and M. Jackson (2004), "The effects of social networks on employment and inequality," American Economic Review 94, 426-454.

[30] Calvó-Armengol, A., Patacchini, E. and Y. Zenou (2009), "Peer effects and social networks in education," Review of Economic Studies 76, 1239-1267.

[31] Card, D. and J. Rothstein (2007), "Racial segregation and the black-white test score gap," Journal of Public Economics 91, 2158-2184.

[32] Cervero, R., Sandoval, O. and J. Landis (2002), "Transportation as a stimulus of welfareto-work. Private versus public mobility," Journal of Planning Education and Research 22, $50-63$.

[33] Coulson, E., Laing, D. and P. Wang (2001), "Spatial mismatch in search equilibrium," Journal of Labor Economics 19, 949-972.

[34] Currarini, S., Jackson, M.O., and P. Pin (2009), "An economic model of friendship: Homophily, minorities, and segregation," Econometrica 77, 1003-1045.

[35] Cutler, D.M. and E.L. Glaeser (1997), "Are ghettos good or bad?" Quarterly Journal of Economics 112, 827-872. 
[36] Cutler, D.M., Glaeser, E.L. and J.L. Vigdor (1999), "The rise and decline of the American gheto," Journal of Political Economy 107, 455-506.

[37] Del Bello, C.L., Patacchini, E. and Y. Zenou (2015), "Social and geographical distance in the analysis of peer effects," IZA Discussion Paper No. 8956.

[38] Fieldhouse, E.A. (1999), "Ethnic minority unemployment and spatial mismatch: The case of London," Urban Studies 36, 1569-1596.

[39] Fujita, M. and H. Ogawa (1980), "Equilibrium land use patterns in a nonmonocentric city," Journal of Regional Science 20, 455-475.

[40] Fujita, M. and J.-F. Thisse (2013), Economics of Agglomeration. Cities, Industrial Location, and Regional Growth, 2nd Edition, Cambridge: Cambridge University Press.

[41] Galenianos, M. (2014), "Hiring through referrals," Journal of Economic Theory 152, 304-323.

[42] Givord, P., Rathelot, R. and P. Sillard (2013), "Place-based tax exemptions and displacement effects : An evaluation of the Zones Franches Urbaines program," Regional Science and Urban Economics 43, 151-163.

[43] Glaeser, E.L. (1999), "Learning in cities," Journal of Urban Economics 46, 254-277.

[44] Glaeser, E.L., Sacerdote, B. and J.A. Scheinkman (1996), "Crime and social interactions," Quarterly Journal of Economics 111, 508-548.

[45] Glaeser, E.L., Kahn, M.E. and J. Rappaport (2008), "Why do the poor live in cities? The role of public transportation," Journal of Urban Economics 63, 1-24.

[46] Gobillon, L., Selod, H. and Y. Zenou (2007), "The mechanisms of spatial mismatch," Urban Studies 44, 2401-2427.

[47] Gobillon, L., Magnac, T. and H. Selod (2011), "Space and unemployment: the labor-market effects of spatial mismatch," Journal of Applied Econometrics 26, 1079-1112.

[48] Granovetter, M.S. (1973), "The strength of weak ties," American Journal of Sociology 78, $1360-1380$.

[49] Grauwin, S., Goffette-Nagot, F. and P. Jensen (2012), "Dynamic models of residential segregation: An analytical solution," Journal of Public Economics 96, 124-141.

[50] Hellerstein, J.K., Neumark, D. and M. McInerney (2008), "Spatial mismatch or racial mismatch?" Journal of Urban Economics 64, 464-479. 
[51] Hellerstein, J.K., McInerney, M. and D. Neumark (2011), "Neighbors and coworkers: The importance of residential labor market networks," Journal of Labor Economics 29, 659-695.

[52] Helsey, R.W. and W.C. Strange (2004), "Knowledge barter in cities," Journal of Urban Economics 56, 327-345.

[53] Helsey, R.W. and W.C. Strange (2007), "Urban interactions and spatial structure," Journal of Economic Geography 7, 119-138.

[54] Helsey, R.W. and W.C. Strange (2014), "Coagglomeration, clusters and the scale and composition of cities," Journal of Political Economy 122, 1064-1093.

[55] Helsley, R.W. and Y. Zenou (2014), "Social networks and interactions in cities," Journal of Economic Theory 150, 426-466.

[56] Holzer, H.J. (1987), "Informal job search and black youth unemployment," American Economic Review 77, 446-452.

[57] Holzer, H.J. (1988), "Search method used by unemployed youth," Journal of Labor Economics $6,1-20$.

[58] Holzer H. J. (1998), "Why do small establishments hire fewer blacks than larger ones?" Journal of Human Resources 33, 896-814.

[59] Holzer, H.J. and K.R. Ihlanfeldt (1996), "Spatial factors and the employment of blacks at the firm level," New England Economic Review 65-86.

[60] Holzer H.J. and Ihlanfeldt, K.R. (1998), "Customer discrimination and the employment outcomes of minority workers," Quarterly Journal of Economics 113, 835-867.

[61] Holzer, H. and Reaser, J. (2000), "Black applicants, black employees, and urban labor market policy," Journal of Urban Economics 48, 365-387.

[62] Ihlanfeldt, K.R. (2006), "A primer on spatial mismatch within urban labor markets," In: R. Arnott and D. McMillen (Eds.), A Companion to Urban Economics, Boston: Blackwell Publishing, pp. 404-417.

[63] Ihlanfeldt, K. R. and D. Sjoquist (1998), "The spatial mismatch hypothesis: A review of recent studies and their implications for welfare reform," Housing Policy Debate 9, 849-892.

[64] Ioannides, Y.M. (2012), From Neighborhoods to Nations: The Economics of Social Interactions, Princeton: Princeton University Press.

[65] Ioannides, Y.M. and D.L. Loury (2004), "Job information networks, neighborhood effects, and inequality," Journal of Economic Literature 42, 1056-1093. 
[66] Ioannides, Y.M. and G. Topa (2010), "Neighborhood effects: Accomplishments and looking beyond them," Journal of Regional Science 50, 343-362.

[67] Jackson, M.O. (2008), Social and Economic Networks, Princeton: Princeton University Press.

[68] Jackson, M.O. and Y. Zenou (2015), "Games on networks, "In: P. Young and S. Zamir (Eds.), Handbook of Game Theory, Vol. 4, Amsterdam: Elsevier, pp. 91-157.

[69] Kain, J. (1968), "Housing segregation, negro employment, and metropolitan decentralization," Quarterly Journal of Economics 82, 175-197.

[70] Katz, L.F., Kling, J.R. and J.B. Liebman (2001), "Moving to opportunity in Boston: Early results of a randomized mobility experiment," Quarterly Journal of Economics 116, 607-654.

[71] Kline, P. and E. Moretti (2014), "People, places, and public policy: Some simple welfare economics of local economic development programs," Annual Review of Economics 6, 629662.

[72] Kling, J.R., Ludwig, J. and L.F. Katz (2005), "Neighborhood effects on crime for female and male youth: Evidence from a randomized housing voucher experiment," Quarterly Journal of Economics 120, 87-130.

[73] Leonard, J. (1990), "The impact of Affirmative Action regulation and Equal Opportunity law on black employment," Journal of Economic Perspectives 4, 47-54.

[74] Lucas, R.E. and E. Rossi-Hansberg (2002), "On the internal structure of cities," Econometrica $70,1445-1476$.

[75] Marmaros, D. and B.I. Sacerdote (2006), "How do friendships form?" Quarterly Journal of Economics 121, 79-119.

[76] Mauer, D.C. and S.H. Ott (1999), "On the optimal structure of government subsidies for entreprise zones and other locational development programs," Journal of Urban Economics $45,421-450$.

[77] Mencken, F.C. and I. Winfield (1998), "In search of the "right stuff": The advantages and disadvantages of informal and formal recruiting practices in external labor markets," American Journal of Economics and Sociology 57, 135-153.

[78] Mossay, P. and P.M. Picard (2011), "On spatial equilibria in a social interaction model," Journal of Economic Theory 146, 2455-2477.

[79] Mossay, P. and P.M. Picard (2013), "Spatial segregation and urban structure," CREA Discussion Paper Series 13-03, Center for Research in Economic Analysis, University of Luxemburg. 
[80] Neumark, D. and H. Simpson (2015), "Place-based policies," In: G. Duranton, V. Henderson and W. Strange (Eds.), Handbook of Regional and Urban Economics, Vol. 5B, Amsterdam: Elsevier Publisher, pp. 1197-1288.

[81] Ong, P. (2002), "Car ownership and welfare-to-work," Journal of Policy Analysis and Management 21, 239-252.

[82] Papke, L. (1994), "Tax policy and urban development: evidence from the Indiana enterprise zone program," Journal of Public Economics 54, 37-49.

[83] Patacchini, E. and Y. Zenou (2012), "Ethnic networks and employment outcomes," Regional Science and Urban Economics 42, 938-949.

[84] Patacchini, E. and Y. Zenou (2015), "Racial identity and education in social networks," Social Networks, forthcoming.

[85] Patacchini, E., Picard, P.M. and Y. Zenou (2015), "Urban social structure, social capital and spatial proximity", CEPR Discussion Paper No. 10501.

[86] Pellizzari, M. (2010), "Do friends and relatives really help in getting a good job?" Industrial and Labor Relations Review 63, 494-510.

[87] Quillian, L. and M.E. Campbell (2003), "Beyond black and white: The present and future of multiracial friendship segregation," American Sociology Review 68, 540-566.

[88] Rosenbaum, E. and L.E. Harris (2001), "Residential mobility and opportunities: Early impacts of the Moving to Opportunity demonstration program in Chicago," Quarterly Journal of Economics 12, 321-346.

[89] Rosenthal, S.S. and W.C. Strange (2003), "Geography, industrial organization, and agglomeration," Review of Economics and Statistics 85, 377-393.

[90] Rosenthal, S.S. and W.C. Strange (2008), "The attenuation of human capital externalities," Journal of Urban Economics 64, 373-389.

[91] Ross, S.L. (1998), "Racial differences in residential and job mobility: Evidence concerning the spatial mismatch hypothesis," Journal of Urban Economics 43, 112-135.

[92] Ross, S.L. (2012), "Social interactions within cities: Neighborhood environments and peer relationships," In: N. Brooks, K. Donaghy and G.-J. Knapp (Eds.), The Oxford Handbook of Urban Economics and Planning, Oxford: Oxford University Press, pp. 203-229.

[93] Sanchez, T.W. (1998), "Equity analysis of personal transportation system benefits," Journal of Urban Affairs 20, 69-86. 
[94] Sanchez, T.W. (1999), "The connection between public transit and employment. The cases of Portland and Atlanta," Journal of the American Planning Association 65, 284-296.

[95] Sato, Y. and Y. Zenou (2015), "How urbanization affect employment and social interactions," European Economic Review 75, 131-155.

[96] Schelling, T.C. (1971), "Dynamic models of segregation," Journal of Mathematical Sociology 1, 143-186.

[97] Sigelman, L., Bledsoe, T., Welch, S., and M.W. Combs (1996), "Making contact? Black-white social interaction in an urban setting," American Journal of Sociology 101, 1306-1332.

[98] Topa, G. (2001), "Social interactions, local spillovers and unemployment," Review of Economic Studies 68, 261-295.1.

[99] Topa, G. and Y. Zenou (2015), "Neighborhood versus network effects", In: G. Duranton, V. Henderson and W. Strange (Eds.), Handbook of Regional and Urban Economics, Vol. 5A, Amsterdam: Elsevier Publisher, pp. 561-624.

[100] Tuch, S.A., Sigelman, L. and J.A. Macdonald (1999), "Trends: Race relations and America youth, 1976-1995," Public Opinion Quarterly 63, 109-148.

[101] Verdier, T. and Y. Zenou (2004), "Racial beliefs, location and the causes of crime," International Economic Review 45, 731-760.

[102] Wasmer, E. and Y. Zenou (2002), "Does city structure affect search and welfare?" Journal of Urban Economics 51, 515-541.

[103] Wilson, W. (1996), When Work Disappears: The World of the New Urban Poor, New York: Alfred A. Knopf.

[104] Zenou, Y. (2006), "Efficiency wages and unemployment in cities: The case of high relocation costs," Regional Science and Urban Economics 36, 49-71.

[105] Zenou, Y. (2009), Urban Labor Economics, Cambridge: Cambridge University Press.

[106] Zenou, Y. (2013), "Spatial versus social mismatch," Journal of Urban Economics 74, 113-132.

[107] Zenou, Y. (2015), "A dynamic model of weak and strong ties in the labor market," Journal of Labor Economics, forthcoming.

[108] Zhang, J. (2004), "Residential segregation in an all-integrationist world," Journal of Economic Behavior and Organization 54, 533-550. 


\section{Appendix: Proofs}

Proof of Proposition 2: Existence and uniqueness: Denote

$$
\Phi(E) \equiv\left(1-\frac{E}{P}\right) \sqrt{\frac{E}{P}}
$$

which is the left-hand side of (23). It is easily checked that $\Phi(0)=\Phi(P)=0$ and that, by solving $\Phi^{\prime}(E)=0$, we obtain: $E=P / 3$ with

$$
\Phi(P / 3)=\frac{2}{3} \sqrt{\frac{1}{3}}=0.384
$$

Since $\Gamma(P)$ is constant and does not depend on $E$, then, as shown in Figure 1, there exists an equilibrium if only if $\Gamma(P)<0.384$, which yields $(25)$.

To ensure that all workers have positive employment probabilities, we must still check that the commuting and search costs of a worker at the city edge outweigh her probability of finding and taking a job. This is given by (13), which can now be written as:

$$
\frac{c(b)}{w-t b}<\frac{\alpha}{\beta} \frac{E}{P}
$$

Observe that, using (16), we have: $c(b)=c(P / 2)=\tau P / 2$. Thus, this inequality is equivalent to:

$$
\frac{\alpha}{\beta} \frac{E}{P}(w-t b)>\frac{\tau P}{2}
$$

Since $E$ increases with $w$, this inequality is always true if $w$ is large enough.

Finally, as shown in Figure 1, for a given $P$, equation (23) gives two solutions of $E / P$ for which $E / P>0$ : one with a high employment rate, $E^{*} / P>1 / 3$, and another with a low employment rate solution $E^{*} / P<1 / 3$. Note that there is also a third equilibrium at $E^{*} / P=0$ where $e_{i}^{*}(x)=$ $n_{i}^{*}(x)=0$, which is ruled out by condition (13). The high employment equilibrium would be the one chosen by workers if they can coordinate on the equilibrium. ${ }^{27}$ Because in most modern economies, the employment rate is above 33.33 percent, we focus on the equilibrium for which $1 / 3<E^{*} / P<1$.

Comparative statics: Observe that the left-hand side of (23), i.e. $\Phi(E)$, is not affected by $t, \tau$, and $w$. Using (16) in (24), one can write $\Gamma(P)$ as:

$$
\Gamma(P)=\sqrt{\frac{\beta}{\alpha(P)}} \frac{1}{P} \int_{-P / 2}^{P / 2} \sqrt{\frac{\frac{\tau}{P}\left(\frac{P^{2}}{4}+x^{2}\right)}{w-t|x|}} \mathrm{d} x
$$

It can be seen that $\Gamma(P)$ increases with $\tau$ and $t$ but decreases with $w$. As a result, when $t, \tau$ increases, $\Gamma(P)$ increases and the line of $\Gamma(P)$ is shifted upward in Figure 1 and thus employment $E^{*}$ decreases. Similarly, $E^{*}$ increases with $\alpha / \beta$.

\footnotetext{
${ }^{27}$ Note that the low employment equilibrium can also be shown to be unstable in the context of migration (open city) and asymptotic stability (close city).
} 
Proof of Proposition 5: We can proceed as in the proof of Proposition 2. Since $\Phi\left(E_{i}\right)$ is still defined by (54), with subscript $i$ on the $E$ s and the $P \mathrm{~s}$, then there is a unique equilibrium for which $1 / 3<E_{1}^{*} / P_{1}<1$ and $1 / 3<E_{2}^{*} / P_{2}<1$ if

$$
\max \left\{\Gamma_{1}\left(P_{1}\right), \Gamma_{2}\left(P_{1}, P_{2}\right)\right\}<0.384
$$

holds, which is (39). The first constraint, $\Gamma_{1}\left(P_{1}\right)<0.384$, puts the same bound as for the homogenous-population case. If network effects are not too important, $\Gamma_{1}\left(P_{1}\right)$ is an increasing function and the above condition sets a upper bound on population $1, \bar{P}_{1} \equiv \Gamma_{1}^{-1}(0.384)$ where $\Gamma_{1}^{-1}$ is the inverse of the function $\Gamma_{1}\left(P_{1}\right)$. Otherwise, it defines an interval, of the form $\left[\bar{P}_{a}, \bar{P}_{b}\right]$ with $\bar{P}_{a}<\bar{P}_{b} \leq w / t$.

The second constraint, $\Gamma_{2}\left(P_{1}, P_{2}\right)<0.384$, puts another bound for population 2 . If network effects are not too important, $\Gamma_{2}\left(P_{1}, P_{2}\right)$ is an increasing function of $P_{2}$ so that the above condition sets an upperbound $\bar{P}_{2}\left(P_{1}\right) \equiv \Gamma_{2}^{-1}\left(P_{1}, 0.384\right)$ where $\Gamma_{2}^{-1}$ is the inverse of the function $\Gamma_{2}\left(P_{1}, P_{2}\right)$ w.r.t the second argument. The upper bound $\bar{P}_{2}\left(P_{1}\right)$ falls with $P_{1}$, from $\bar{P}_{1}$ at $P_{1}=0$ to zero at some threshold population $\underline{P}_{1}$. One can check that $\bar{P}_{2}(0)=\bar{P}_{1}$ where $\underline{P}_{1}$ is such that $\Gamma_{2}\left(\underline{P}_{1}, 0\right)=0.384$. It can be checked that $\underline{P}_{1}<\bar{P}_{1}$. Therefore, condition (39) holds if $P_{1}<\bar{P}_{1}$ and $P_{2}<\bar{P}_{2}\left(P_{1}\right)$. Otherwise, if $\Gamma_{2}\left(P_{1}, P_{2}\right)$ is a decreasing function of $P_{2}$, the condition sets lower bound.

We also need to check that there are no corner solutions. The conditions are given by (35), which are:

$$
\frac{c_{1}\left(P_{1} / 2\right)}{w-t P_{1} / 2}<\frac{\alpha_{1}}{\beta} \frac{E_{1}}{P_{1}}
$$

and

$$
\frac{c_{2}\left(\left(P_{1}+P_{2}\right) / 2\right)}{w-t\left(P_{1}+P_{2}\right) / 2}<\frac{\alpha_{2}}{\beta} \frac{E_{2}}{P_{2}}
$$

Since the equilibrium employment level rises with higher wage $w$, the RHS of each condition rises with $w$ while the LHS falls with it. The conditions are then satisfied for sufficiently high $w$.

Proof of Proposition 6: We need to check when this urban structure is a spatial equilibrium in the city with populations $P_{1}$ and $P_{2}$. As shown in Figure 2 and by condition (30), in equilibrium, the individuals from population 1 must bid for the highest land prices around the city center (for $x$ such that $-b_{1} \leq x \leq b_{1}$ ) and population 2 must offer the highest land prices at the periphery (for $x$ such that $-b_{2} \leq x \leq-b_{1}$ and $b_{1} \leq x \leq b_{2}$ ). Since the city is symmetric, we only need to check the following land market conditions:

$$
\Psi_{1}\left(x, u_{1}\right) \geq \Psi_{2}\left(x, u_{2}\right) \quad \text { for } x \in\left[0, b_{1}\right]
$$

and

$$
\Psi_{1}\left(x, u_{1}\right) \leq \Psi_{2}\left(x, u_{2}\right) \quad \text { for } x \in\left[b_{1}, b_{2}\right]
$$


The land market imposes the continuity of bid rents (see (30)) so that $\Psi_{1}\left(b_{1}, u_{1}\right)=\Psi_{2}\left(b_{1}, u_{2}\right)$ and $\Psi_{2}\left(b_{2}, u_{2}\right)=0$. These two conditions yield the equilibrium utility levels $u_{1}^{*}$ and $u_{2}^{*}$. From (15) we know that the land gradient is given by

$$
\Psi_{i}^{\prime}\left(x, u_{i}\right)=-e_{i}^{*}(x) t-n_{i}^{*}(x) c_{i}^{\prime}(x)
$$

which is negative for any $x \geq 0, i=1,2$ because $c_{i}^{\prime}(x)>0$.

First, let us check that, on the interval $\left[0, b_{1}\right], \Psi_{1}\left(x, u_{1}\right) \geq \Psi_{2}\left(x, u_{2}\right)$. On the interval $\left[0, b_{1}\right]$, we can use the condition $\Psi_{1}\left(b_{1}, u_{1}\right)=\Psi_{2}\left(b_{1}, u_{2}\right)$ to write the difference in bid rents as

$$
\Psi_{1}\left(x, u_{1}\right)-\Psi_{2}\left(x, u_{2}\right)=-\int_{x}^{b_{1}}\left[\Psi_{1}^{\prime}\left(x, u_{1}\right)-\Psi_{2}^{\prime}\left(x, u_{2}\right)\right] \mathrm{d} x
$$

which is positive because the integrand

$$
\Psi_{1}^{\prime}(x)-\Psi_{2}^{\prime}(x)=-\left[e_{1}^{*}(x)-e_{2}^{*}(x)\right] t-n_{1}^{*}(x) c_{1}^{\prime}(x)
$$

is negative since $c_{2}^{\prime}(x)=0$ while $c_{1}^{\prime}(x)>0$ and $e_{1}^{*}(x)>e_{2}^{*}(x)$ in the absence of network size effects. As a result, $\Psi_{1}\left(x, u_{1}\right) \geq \Psi_{2}\left(x, u_{2}\right)$ on this interval. Population 2 is never able to bid away population 1 in the vicinity of the city center. This is because they lose access to their own members and therefore have higher interaction costs than population 1.

Second, let us check that, on the interval $\left(b_{1}, b_{2}\right], \Psi_{1}\left(x, u_{1}\right) \leq \Psi_{2}\left(x, u_{2}\right)$. This is equivalent to

$$
\Psi_{1}\left(x, u_{1}\right)-\Psi_{2}\left(x, u_{2}\right)=\int_{b_{1}}^{x}\left[\Psi_{1}^{\prime}\left(x, u_{1}\right)-\Psi_{2}^{\prime}\left(x, u_{2}\right)\right] \mathrm{d} x \leq 0
$$

where

$$
\Psi_{1}^{\prime}\left(x, u_{1}\right)-\Psi_{2}^{\prime}\left(x, u_{2}\right)=-\left[e_{1}^{*}(x)-e_{2}^{*}(x)\right] t-n_{1}^{*}(x) \tau+n_{2}^{*}(x) c_{2}^{\prime}(x)
$$

which is equivalent to

$$
\Psi_{1}^{\prime}\left(x, u_{1}\right)-\Psi_{2}^{\prime}\left(x, u_{2}\right)=-\left[e_{1}^{*}(x)-e_{2}^{*}(x)\right] t-n_{1}^{*}(x) \tau+n_{2}^{*}(x) \tau\left(\frac{x-b_{1}}{b_{2}-b_{1}}\right)
$$

Since $e_{1}^{*}(x)>e_{2}^{*}(x)$ in the absence of network size effects, this expression is negative at $x=b_{1}$ and, by continuity, it is also negative for slightly larger $x$. For this reason, the individuals from population 2 residing close to $x=b_{1}$ will have no incentives to outbid population 1 . This will occurs if $b_{2}$ is close to $b_{1}$, that is if the size of population $2, P_{2}$, is small enough. Therefore, there exists a threshold $\widehat{P}_{2}\left(P_{1}\right)>0$ so that the land market conditions are satisfied if $P_{2}<\widehat{P}_{2}\left(P_{1}\right)$. In general, we must write condition (55) for the closed city urban equilibrium under segregation to exist.

Proof of Proposition 7: Suppose the existence of network size effects: $\alpha_{i}=\alpha\left(P_{i}\right)$ with $\alpha^{\prime}\left(P_{i}\right)>0$. We prove that there exists a population size $P_{1}$ such that $E_{1} / P_{1}>E_{2} / P_{2}$ under the conditions that $\alpha(0)=0$ and $P \alpha^{\prime}(0) / \alpha(P)<0.2177$. 
We first characterize the RHS of (40). Let us first define the function

$$
\Phi(a, b)=\int_{0}^{1} \sqrt{\frac{1+a z^{2}}{1-b z}} \mathrm{~d} z
$$

This integral has no explicit expression. It can nevertheless numerically be shown for all arguments that $\Phi(a, b)>0$ while $\Phi(a, b)$ is concave increasing in $a$ and convex increasing in $b$. Also, we have $\Phi(0,0)=1, \Phi(0,1)=2, \Phi(1,1)=2.459$ and $\Phi(1,0)=1.14779$, while $\Phi(a, 0)>1$.

Lemma 1 We have:

$$
\frac{1}{P_{1}} \int_{0}^{P_{1} / 2} \sqrt{\frac{c_{1}(x)}{w-t|x|}} \mathrm{d} x=\sqrt{\frac{\tau P_{1}}{16 w}} \Phi\left(1, \frac{t P_{1}}{2 w}\right)
$$

and

$$
\frac{1}{P_{2}} \int_{P_{1} / 2}^{\left(P_{1}+P_{2}\right) / 2} \sqrt{\frac{c_{2}(x)}{w-t|x|}} \mathrm{d} x=\frac{1}{2} \sqrt{\frac{\tau\left(2 P_{1}+P_{2}\right)}{4\left(w-t P_{1} / 2\right)}} \Phi\left(\frac{P_{2}}{2 P_{1}+P_{2}}, \frac{t P_{2}}{2 w-t P_{1}}\right)
$$

Proof: We compute

$$
\begin{aligned}
\frac{1}{P_{1}} \int_{0}^{P_{1} / 2} \sqrt{\frac{c_{1}(x)}{w-t|x|}} \mathrm{d} x & =\frac{1}{2 b_{1}} \sqrt{\frac{\tau}{2 b_{1}}} \int_{0}^{b_{1}} \sqrt{\frac{b_{1}^{2}+x^{2}}{w-t x}} \mathrm{~d} x \\
& =\sqrt{\frac{\tau b_{1}}{8 w}} \int_{0}^{1} \sqrt{\frac{1+z^{2}}{1-\frac{t b_{1}}{w} z}} \mathrm{~d} z \\
& =\sqrt{\frac{\tau b_{1}}{8 w}} \Phi\left(1, \frac{t b_{1}}{w}\right) \\
& =\sqrt{\frac{\tau P_{1}}{16 w}} \Phi\left(1, \frac{t P_{1}}{2 w}\right)
\end{aligned}
$$


and

$$
\begin{aligned}
& \frac{1}{P_{2}} \int_{P_{1} / 2}^{\left(P_{1}+P_{2}\right) / 2} \sqrt{\frac{c_{2}(x)}{w-t|x|}} \mathrm{d} x=\frac{1}{P_{2}} \sqrt{\frac{\tau}{2\left(b_{2}-b_{1}\right)}} \int_{b_{1}}^{b_{2}} \sqrt{\frac{\left(b_{2}^{2}-2 b_{1} x+x^{2}\right)}{w-t x}} \mathrm{~d} x \\
& =\frac{1}{P_{2}} \sqrt{\frac{\tau}{2\left(b_{2}-b_{1}\right)}} \int_{0}^{b_{2}-b_{1}} \sqrt{\frac{\left(b_{2}^{2}-2 b_{1}\left(z+b_{1}\right)+\left(z+b_{1}\right)^{2}\right)}{w-t\left(z+b_{1}\right)}} \mathrm{d} z \\
& =\frac{1}{P_{2}} \sqrt{\frac{\tau}{2}\left(b_{2}-b_{1}\right)} \int_{0}^{1} \sqrt{\frac{b_{2}^{2}-2 b_{1}\left(\left(b_{2}-b_{1}\right) y+b_{1}\right)+\left(\left(b_{2}-b_{1}\right) y+b_{1}\right)^{2}}{w-t\left(\left(b_{2}-b_{1}\right) y+b_{1}\right)}} \mathrm{d} y \\
& =\frac{1}{P_{2}} \sqrt{\frac{\tau}{2}}\left(b_{2}-b_{1}\right) \int_{0}^{1} \sqrt{\frac{\left(b_{1}+b_{2}+y^{2}\left(b_{2}-b_{1}\right)\right)}{w-t b_{1}-t\left(b_{2}-b_{1}\right) y}} \mathrm{~d} y \\
& =\frac{1}{P_{2}} \sqrt{\frac{\tau\left(b_{1}+b_{2}\right)}{2\left(w-t b_{1}\right)}}\left(b_{2}-b_{1}\right) \int_{0}^{1} \sqrt{\frac{1+\frac{b_{2}-b_{1}}{b_{1}+b_{2}} z^{2}}{1-t \frac{b_{2}-b_{1}}{w-t b_{1}} z}} \mathrm{~d} z \\
& =\frac{1}{P_{2}} \sqrt{\frac{\tau\left(b_{1}+b_{2}\right)}{2\left(w-t b_{1}\right)}}\left(b_{2}-b_{1}\right) \Phi\left(\frac{b_{2}-b_{1}}{b_{1}+b_{2}}, t \frac{b_{2}-b_{1}}{w-t b_{1}}\right) \\
& =\frac{1}{2} \sqrt{\frac{\tau\left(2 P_{1}+P_{2}\right)}{4\left(w-t P_{1} / 2\right)}} \Phi\left(\frac{P_{2}}{2 P_{1}+P_{2}}, \frac{t P_{2}}{2 w-t P_{1}}\right)
\end{aligned}
$$

This proves the results.

With this lemma, we can write the RHS of (40) as

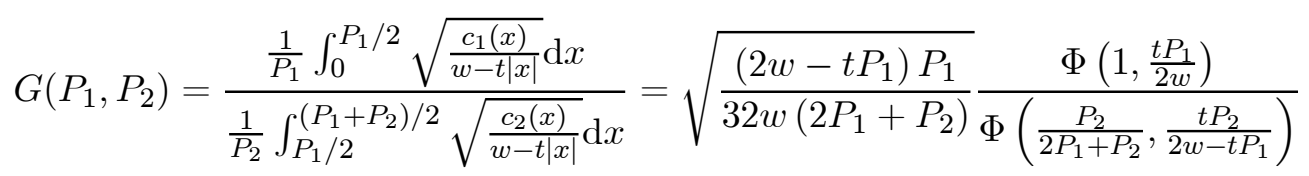

Denoting $P=P_{1}+P_{1}$, we readily get

$$
\begin{aligned}
& G(P, 0)=0 \\
& G(P, 0)=\frac{1}{4} \sqrt{\frac{w-t P / 2}{2 w}} \frac{\Phi\left(1, \frac{t P}{2 w}\right)}{\Phi(0,0)} \in(0,0.4331)
\end{aligned}
$$

The graph of $G(P, 0)$ lies in the interval $(0,0.4331)$ because $\Phi(0,0)=1, \Phi(1,1)=2.459, t P / 2<w$ and $\Phi(a, b)$ is an increasing function of $b$. So, $G(P, 0)$ is bounded by 0.4331 . Also, denoting $P_{1}=\lambda P$ and $P_{2}=(1-\lambda) P$, we write

$$
G(\lambda P,(1-\lambda) P)=\sqrt{\lambda} \sqrt{\frac{(2 w-t \lambda P)}{32 w(\lambda+1)}} \frac{\Phi\left(1, \lambda \frac{t P}{2 w}\right)}{\Phi\left(\frac{1-\lambda}{\lambda+1}, \frac{(1-\lambda) t P}{2 w-\lambda t P}\right)}
$$

For small enough $\lambda$, this function tends to

$$
G(\lambda P,(1-\lambda) P) \simeq \sqrt{\lambda} A\left(\frac{t P}{2 w}\right)
$$


where

$$
A(b) \equiv \sqrt{\frac{1}{32}} \frac{\Phi(1,0)}{\Phi\left(1, \frac{t P}{2 w}\right)}
$$

is a decreasing concave function of $b$ taking values in the interval $(0.4666,1)$.

We then characterize the LHS of (40). Let us set

$$
H(\lambda)=\sqrt{\frac{\alpha\left(P_{1}\right)}{\alpha\left(P_{2}\right)}}=\sqrt{\frac{\alpha(\lambda P)}{\alpha((1-\lambda) P)}}
$$

and let assume that $\alpha(0)=0$. So, $H(0)=0$ and $H(1)=+\infty$.

Finally, the population $P_{1}=\lambda P$ has higher aggregate employment if and only if

$$
H(\lambda) \leq G(\lambda P,(1-\lambda) P)
$$

Observe that $H(0)=G(0, P)$ and $H(1)>G(P, 0)$. So, a sufficient condition for this inequality to hold is that, for sufficiently small $\lambda$,

$$
\frac{\alpha(\lambda P)}{\alpha((1-\lambda) P)}<\lambda\left(A\left(\frac{t P}{2 w}\right)\right)^{2}
$$

which holds if

$$
\frac{d}{d \lambda}\left(\frac{\alpha(\lambda P)}{\alpha((1-\lambda) P)}\right)<\left(A\left(\frac{t P}{2 w}\right)\right)^{2}
$$

Applied at $\lambda=0$, this yields

$$
\frac{P \alpha^{\prime}(0)}{\alpha(P)}<\left(A\left(\frac{t P}{2 w}\right)\right)^{2}
$$

Since $A\left(\frac{t P}{2 w}\right)>0.4666$, a sufficient condition is that

$$
\frac{P \alpha^{\prime}(0)}{\alpha(P)}<0.2177
$$

Example: Suppose assume $\alpha(P)=\alpha_{0} P^{\theta}$ so that $\alpha^{\prime}(P)=\alpha_{0} \theta P^{\theta-1}$. Then condition (57) is true for all $\theta>1$. If $\theta \leq 1$, we can use condition (56) so that

$$
\frac{\lambda^{\theta-1}}{(1-\lambda)^{\theta}}<\left(A\left(\frac{t P}{2 w}\right)\right)^{2}
$$

However, this is never satisfied for $A\left(\frac{t P}{2 w}\right) \in[0.4666,1]$. The following table gives the minimal and maximal ranges for which the central population has a larger aggregate employment rate for various network effect parameters $\theta$. In this table, the range is the open intervals $(0, \lambda)=\left(0, P_{1} / P\right)$ where $\lambda$ solves the binding condition (58) evaluated at $A\left(\frac{t P}{2 w}\right)=0.4666$ and $A\left(\frac{t P}{2 w}\right)=1$. 


\begin{tabular}{ccc}
\hline \hline$\theta$ & $\left(0, \min P_{1} / P\right)$ & $\left(0, \max P_{1} / P\right)$ \\
\hline 1. & $(0.00,0.00)$ & $(0.00,0.00)$ \\
1.4 & $(0.00,0.10)$ & $(0.00,0.29)$ \\
1.8 & $(0.00,0.22)$ & $(0.00,0.36)$ \\
2.2 & $(0.00,0.29)$ & $(0.00,0.40)$ \\
2.6 & $(0.00,0.33)$ & $(0.00,0.42)$ \\
3. & $(0.00,0.35)$ & $(0.00,0.43)$ \\
$\ldots$ & $\ldots$ & $\ldots$ \\
$\infty$ & $(0.00,0.50)$ & $(0.00,0.50)$ \\
\hline \hline
\end{tabular}

Table A1: Minimal and maximal ranges for which the central population has larger aggregate employment rate. Network size effect: $\alpha(P)=\alpha_{0} P^{\theta}$.

\section{Proof of Proposition 8}

(i) The integrated city equilibrium exists only for population with symmetric sizes. In that case, the social-interaction costs are the same for the two populations so that $c_{i}(x)=c_{j}(x)=c(x)$. As seen in Section 5.1, the aggregate employments are such that $\alpha_{i} E_{i} / P_{i}=\alpha_{j} E_{j} / P_{j}$. As a result, the condition $c_{i}(x) /\left(\alpha_{i} E_{i} / P_{i}\right)<c_{j}(x) /\left(\gamma \alpha_{i} E_{j} / P_{j}\right)$ is equivalent to $\gamma<1$, which is true by assumption. The optimal choice is not to interact with each other so that $n_{i j}^{*}(x)=0$.

(ii) Consider now the segregated city equilibrium where population 1 resides in the centered interval $\left[-b_{1}, b_{1}\right]$ and population 2 in the periphery intervals $\left[-b_{2},-b_{1}\right) \cup\left(b_{1}, b_{2}\right]$ as defined in Definition 2. Let us show under which condition the two populations do not interact with each other.

Because of the symmetry, we can restrict our attention to $x>0$. Population 1 does not interact with population 2 if

$$
\frac{c_{1}(x)}{\alpha_{1} E_{1} / P_{1}}<\frac{c_{2}(x)}{\gamma \alpha_{2} E_{2} / P_{2}} \Leftrightarrow \frac{c_{2}(x)}{c_{1}(x)}>\frac{\gamma \alpha_{2} E_{2} / P_{2}}{\alpha_{1} E_{1} / P_{1}}, \forall x \in\left[0, b_{1}\right]
$$

Population 2 does not interact with population 1 if

$$
\frac{c_{2}(x)}{\alpha_{2} E_{2} / P_{2}}<\frac{c_{1}(x)}{\gamma \alpha_{1} E_{1} / P_{1}} \Leftrightarrow \frac{c_{2}(x)}{c_{1}(x)}<\frac{\alpha_{2} E_{2} / P_{2}}{\gamma \alpha_{1} E_{1} / P_{1}}, \forall x \in\left(b_{1}, b_{2}\right]
$$

Those conditions imply

$$
\min _{x \in\left[0, b_{1}\right]} \frac{c_{2}(x)}{c_{1}(x)}>\frac{\gamma \alpha_{2} E_{2} / P_{2}}{\alpha_{1} E_{1} / P_{1}} \quad \text { and } \max _{x \in\left(b_{1}, b_{2}\right]} \frac{c_{2}(x)}{c_{1}(x)}<\frac{\alpha_{2} E_{2} / P_{2}}{\gamma \alpha_{1} E_{1} / P_{1}}
$$

Given that $c_{2}(x) / c_{1}(x)$ is monotonically decreasing in $x$, for all $x>0$, we compute

$$
\min _{x \in\left[0, b_{1}\right]} \frac{c_{2}(x)}{c_{1}(x)}=\max _{x \in\left(b_{1}, b_{2}\right]} \frac{c_{2}(x)}{c_{1}(x)}=\frac{c_{2}\left(b_{1}\right)}{c_{1}\left(b_{1}\right)}=\frac{2 P_{1}+P_{2}}{2 P_{1}}
$$


This yields the conditions

$$
\frac{2 P_{1}+P_{2}}{2 \gamma P_{1}}>\frac{\alpha_{2} E_{2} / P_{2}}{\alpha_{1} E_{1} / P_{1}}>\gamma \frac{2 P_{1}+P_{2}}{2 P_{1}}
$$

which are reported in (43).

Proof of Proposition 9: As in (2) the employment probability $e(x)$ is defined by:

$$
e(x)=\frac{\pi(x)}{\pi(x)+\beta}
$$

which can be inverted as

$$
\pi(x)=\beta \frac{e(x)}{(1-e(x))}
$$

Using the definition $\vartheta(x) \equiv c(x) /(w-t|x|)$ and the property $g^{\prime}(z)=\beta /(\beta+z)^{2}$, expression (48) can be written as

$$
\pi(x)+\frac{\alpha P}{\beta}(\pi(x)+\beta)^{2} \vartheta(x)=\alpha E
$$

Replacing $\pi(x)$ by (59) we get

$$
\alpha E(1-e(x))^{2}-\beta e(x)(1-e(x))-\alpha \beta P \vartheta(x)=0
$$

which finally can be written as

$$
(\beta+\alpha E)[1-e(x)]^{2}-\beta[1-e(x)]-\alpha \beta P \vartheta(x)=0
$$

The first and last term of (60) are similar to the terms in expression (12), which is obtained in the case of random search. For $c(x)>0$ and $\vartheta(x)>0$, the unique root such that $e \in[0,1]$ yields the following employment rate:

$$
e^{*}(x)=1-\frac{\beta+\sqrt{\beta^{2}+4 \alpha \beta(\beta+\alpha E) P \vartheta(x)}}{2(\beta+\alpha E)}
$$

Replacing $c(x)$ by (16) and $\vartheta(x)$ by $c(x) /(w-t|x|)$ in (61) gives (49). The employment rate $e^{*}(x)$ decreases with larger $\vartheta(x)$ and therefore with $x$ since $\vartheta(x)$ is an increasing function of $x$. For the sake of analytical tractability, we guarantee that $e(x)<1$ by assuming $\vartheta(x) \leq(\alpha / \beta)(E / P)$, which is always true when $w$ is large enough.

Using (61), the equilibrium aggregate employment $E^{*}=\int_{-b}^{b} e^{*}(x) \mathrm{d} x$ writes as

$$
E^{*}=\frac{\left(\beta+2 \alpha E^{*}\right) P-\int_{-b}^{b} \sqrt{\beta^{2}+4 \alpha \beta\left(\beta+\alpha E^{*}\right) P \vartheta(x)} \mathrm{d} x}{2\left(\beta+\alpha E^{*}\right)}
$$

From (62), we further obtain the implicit equation 


$$
2\left(\beta+\alpha E^{*}\right) E^{*}=\left(\beta+2 \alpha E^{*}\right) P-F\left(P, E^{*}\right)
$$

where

$$
F(P, E)=2 \int_{0}^{P / 2} \sqrt{\beta^{2}+4 \alpha \beta\left(\beta+\alpha E^{*}\right) P \frac{\tau\left[(P / 2)^{2}+x^{2}\right]}{w+t x}} \mathrm{~d} x
$$

where the function $F(P, E)$ is an increasing in both arguments. Those expressions yield (50) and (51).

The roots of equation (63) yields the equilibrium employment level $E^{*}$ for a given population $P$. Note first that there exists no equilibrium when $P$ is too large. Indeed, there exists a threshold $\bar{P}>0$ such that the equation accepts no positive root if $P>\bar{P}$. This is because the RHS of (50) falls to negative values whereas the LHS remains positive when $P \rightarrow \infty$. Indeed, for large enough $P$, the square root in (64) tends to a value larger than $\sqrt{4 \alpha \beta(\beta+\alpha E) P \tau / w} \sqrt{(P / 2)^{2}+x^{2}}$ and the integral tends to a value larger than

$$
\begin{aligned}
& \sqrt{16 \alpha \beta(\beta+\alpha E) P \tau / w}(P / 2)^{2} \int_{0}^{1} \sqrt{1+z^{2}} d z \\
& =1.1477(P / 2)^{2} \sqrt{16 \alpha \beta(\beta+\alpha E) P \tau / w}
\end{aligned}
$$

which rises with larger $P$. Note secondly that there is no equilibrium for any too small $P$. To see this, note that $F(P, E)>\beta P$. So, by (63), we have

$$
2\left(\beta+\alpha E^{*}\right) E^{*}>\left(\beta+2 \alpha E^{*}\right) P-\beta P
$$

which implies

$$
\left(\beta+\alpha\left(E^{*}-P\right)\right) E^{*}>0 \Longleftrightarrow E^{*}>P-\frac{\beta}{\alpha}
$$

Therefore for any positive $E^{*}$, this imposes $P>\beta / \alpha$. Therefore, there exists a threshold $\underline{P} \geq \beta / \alpha$ such that the equation accepts no positive root if $P<\underline{P}$.

Let us now show that the employment probability $\pi(x)$ and the frequency of search interactions $n^{*}(x, y)$ decreases with the distance to the job center. For that, consider (48). Because $g($.$) is a$ concave function, the RHS of (48) is a decreasing function of $\pi(x)$ while the LHS is an increasing function of $\pi(x)$. As a result, there is a unique solution for $\pi(x)$. Because the RHS decreases with larger ratio $c(x) /(w-t|x|)$ and because this ratio increases with $x$ and with $\tau$ and $t$, the probability of finding a job $\pi(x)$ decreases with $x$ and with $\tau$ and $t$. Since $e(x)$ increases with $\pi(x)$, the same properties apply for the employment probability $e(x)$.

Finally, let us show that the employment rate $E^{*}$ decreases with larger commuting $t$ and search $\operatorname{costs} \tau$ but increases with wages $w$. Indeed, for $c(x)$ and $\vartheta(x)$ sufficiently close to zero, the employment probability tends to $e^{*}(x)=\alpha E /(\beta+\alpha E)$ and the aggregate employment level is equal to $E=P-\beta / \alpha$. So, there exists a constant frictional unemployment of $\beta / \alpha$ workers. Because 
$\vartheta(x)$ increases with higher $\tau$ and $t$, the aggregate employment $E^{*}$ falls with higher travel cost $\tau$ and commuting cost $t$. A similar argument also applies for $w$.

\section{Heterogenous population with directed search}

The land conditions are similar to those obtained for random search. That is, $\Psi_{1}(x) \geq \Psi_{2}(x)$ for $x \in\left[0, b_{1}\right]$ and $\Psi_{1}(x) \leq \Psi_{2}(x)$ for $x \in\left[b_{1}, b_{2}\right]$. The bid rents can be written as

$$
\Psi_{i}\left(x, u_{i}\right)=e_{i}^{*}(x)(w-t|x|)-\int_{D_{i}} \tau|x-y| n_{i}^{*}(x, y) \mathrm{d} y-u_{i}
$$

The city border conditions $\Psi_{1}\left(b_{1}, u_{1}\right)=\Psi_{2}\left(b_{1}, u_{2}\right)$ and $\Psi_{2}\left(b_{2}, u_{2}\right)=0$ yield the equilibrium utility levels $u_{1}^{*}$ and $u_{2}^{*}$. Applying the envelop theorem, the land gradient is given by

$$
\Psi_{i}^{\prime}\left(x, u_{i}\right)=-e_{i}^{*}(x) \operatorname{tsign}(x)-\int_{D_{i}} \tau n_{i}^{*}(x, y) \operatorname{sign}(x-y) \mathrm{d} y
$$

Is the land rent of each population 1 and 2 is bell-shaped over the whole city support $\left(-b_{2}, b_{2}\right)$ ? We here show that the land rent $\Psi_{1}\left(x, u_{1}\right)$ of population 1 is bell-shaped over the interval $\left(-b_{2}, b_{2}\right)$. We just need to show that the land gradient is negative for $x \in\left(0, b_{2}\right)$. By symmetry it is positive for $x \in\left(-b_{2}, 0\right)$. Note first that the first term of the last expression is negative for $x \in\left(0, b_{2}\right)$. Note second that, for $x \in\left(b_{1}, b_{2}\right)$, the integral in the second term is equal to $\int_{-b_{1}}^{b_{1}} n_{1}^{*}(x, y) \mathrm{d} y$, which is positive. Therefore, $\Psi_{1}^{\prime}\left(x, u_{1}\right)<0$ for any $x \in\left(b_{1}, b_{2}\right)$. Finally note that, for $x \in\left(0, b_{1}\right)$, the integral is proportional to $\int_{-b_{1}}^{x} n_{1}^{*}(x, y) \mathrm{d} y-\int_{x}^{b_{1}} n_{1}^{*}(x, y) \mathrm{d} y$ and is also positive. Indeed, one can substitute the variable $y$ by $x-\varepsilon$ in the first integral, substitute the same variable $y$ by $x+\varepsilon$ in the second integral, inverse the boundaries of the first integral and change its sign to obtain

$$
\int_{0}^{b_{1}+x} n_{1}^{*}(x, x-\varepsilon) \mathrm{d} \varepsilon-\int_{0}^{b_{1}-x} n_{1}^{*}(x, x+\varepsilon) \mathrm{d} \varepsilon
$$

or equivalently

$$
\int_{b_{1}-x}^{b_{1}+x} n_{1}^{*}(x, x-\varepsilon) \mathrm{d} \varepsilon+\int_{0}^{b_{1}-x}\left[n_{1}^{*}(x, x-\varepsilon)-n_{1}^{*}(x, x+\varepsilon)\right] \mathrm{d} \varepsilon
$$

The first term is obviously positive while the second term is also positive because $n_{1}^{*}(x, x-\varepsilon)>$ $n_{1}^{*}(x, x+\varepsilon)$ holds for $0<\varepsilon<b_{1}-x$. The latter inequality indeed holds because as, by (52), $e_{1}^{*}(y)$ falls with larger $|y|$, we have that $e_{1}^{*}(x-\varepsilon)>e_{1}^{*}(x+\varepsilon), \varepsilon \in\left(0, b_{1}-x\right)$, and therefore $n_{1}^{*}(x, x-\varepsilon)>n_{1}^{*}(x, x+\varepsilon)$ since, by $(47), n_{1}^{*}(x, y)$ rises with larger $e_{1}(y)$. In other words, the land rent decreases with distance from the city center because workers lose access to those workers who simultaneously locate about the city center and who have higher employment propability and transmit more job opportunities. 
For the population 2 located at the periphery, the land gradient may not be bell-shaped in $x$ for $x>0$. For instance, at $x=b_{1}$, it is equal to

$$
\Psi_{2}^{\prime}\left(b_{1}, u_{2}\right)=-e_{2}^{*}\left(b_{1}\right) t-\int_{-b_{2}}^{-b_{1}} \tau n_{2}^{*}\left(b_{1}, y\right) \mathrm{d} y+\int_{b_{1}}^{b_{2}} \tau n_{2}^{*}\left(b_{1}, y\right) \mathrm{d} y
$$

which can be negative because the last term is larger than (the absolute value of) the second term. Hence, land rend may have a maximum on the district $\left[b_{1}, b_{2}\right]$. Indeed, workers have fewer incentives to interact with the half of their population located in the district $\left[-b_{2},-b_{1}\right]$. In other words, when the peripheral districts are far away, a worker located in $\left[b_{1}, b_{2}\right]$ does not interact much with workers in the other district $\left[-b_{2},-b_{1}\right]$. She rather wants to take advantage of a better access to the population in $\left[b_{1}, b_{2}\right]$ by locating about at the centre of this interval. In this case, the land bid rent can have two modes over the city support $\left[-b_{2}, b_{2}\right]$.

Since $\Psi_{1}\left(b_{1}\right)=\Psi_{2}\left(b_{1}\right)$, we may write the difference in bid rents as

$$
\Psi_{1}\left(x, u_{1}\right)-\Psi_{2}\left(x, u_{2}\right)=-\int_{x}^{b_{1}}\left[\Psi_{1}^{\prime}\left(x, u_{1}\right)-\Psi_{2}^{\prime}\left(x, u_{2}\right)\right] \mathrm{d} x
$$

where

$\Psi_{1}^{\prime}\left(x, u_{1}\right)-\Psi_{2}^{\prime}\left(x, u_{2}\right)=-\left[e_{1}^{*}(x)-e_{2}^{*}(x)\right] t-\tau \int_{D_{1}} n_{1}^{*}(x, y) \operatorname{sign}(x-y) \mathrm{d} y+\tau \int_{D_{2}} n_{2}^{*}(x, y) \operatorname{sign}(x-y) \mathrm{d} y$

However the latter expression is difficult to sign. 


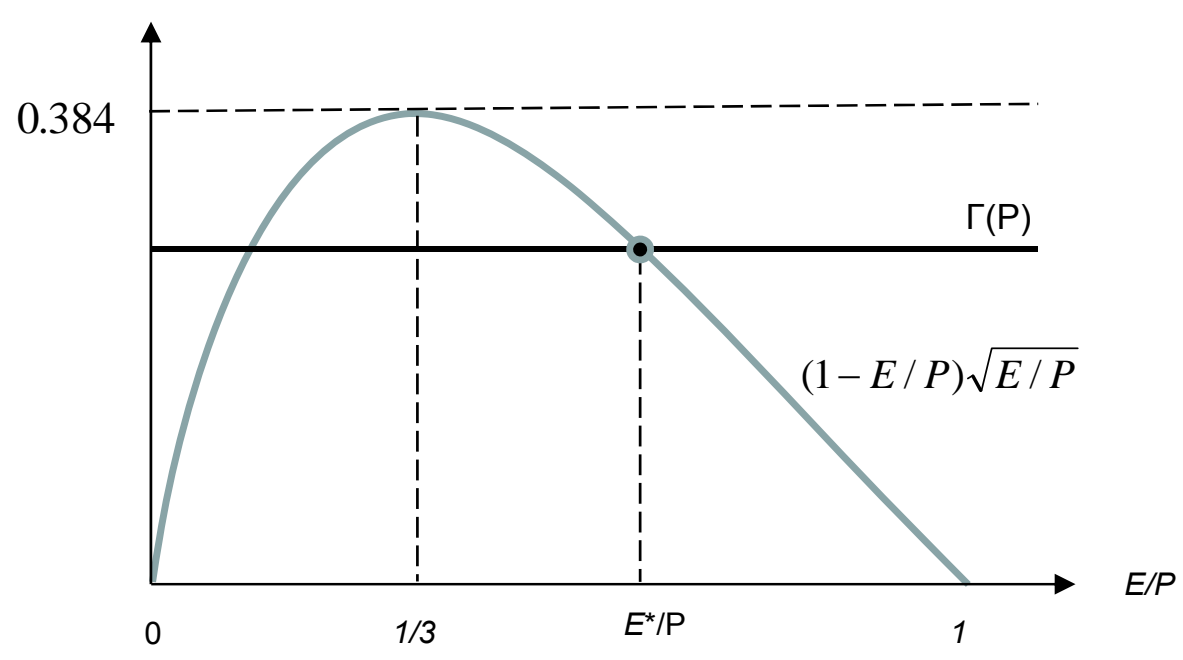

Figure 1: Urban equilibrium with homogeneous population 
Homogeneous population equilibrium: bid rent, employment, number of interactions (log)
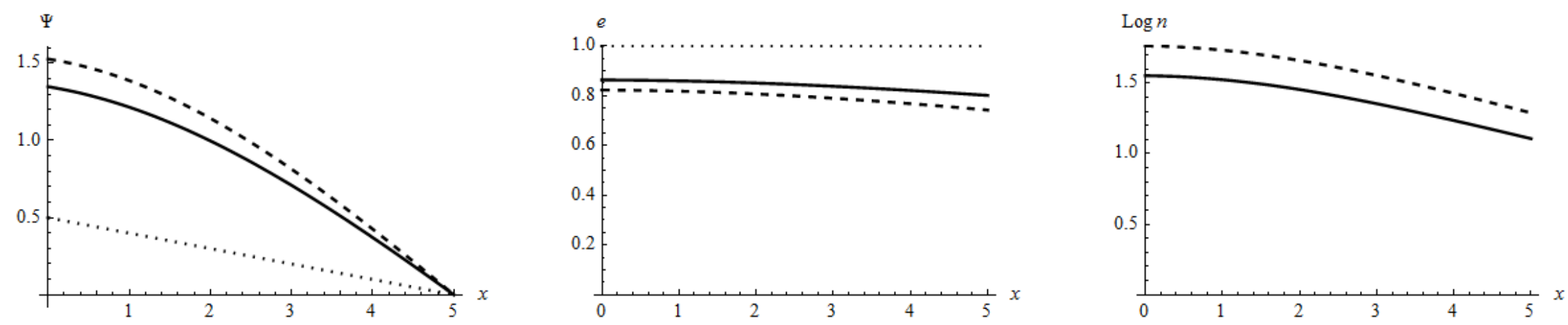

Equilibrium values with network size effects $(\theta=0.2)$ (solid): $E / P=0.841, u=6.099$.

Equilibrium values without network size effects $(\theta=0)$ (dashed): $E / P=0.793, u=5.237$.

Equilibrium values without job uncertainty (dotted): $E / P=1 ., u=9.5$.

Parameters: $P=10, w=10, \alpha=0.1, \beta=0.1, t=0.1, \tau=0.1$.

Figure 2: Urban equilibrium with homogeneous population 


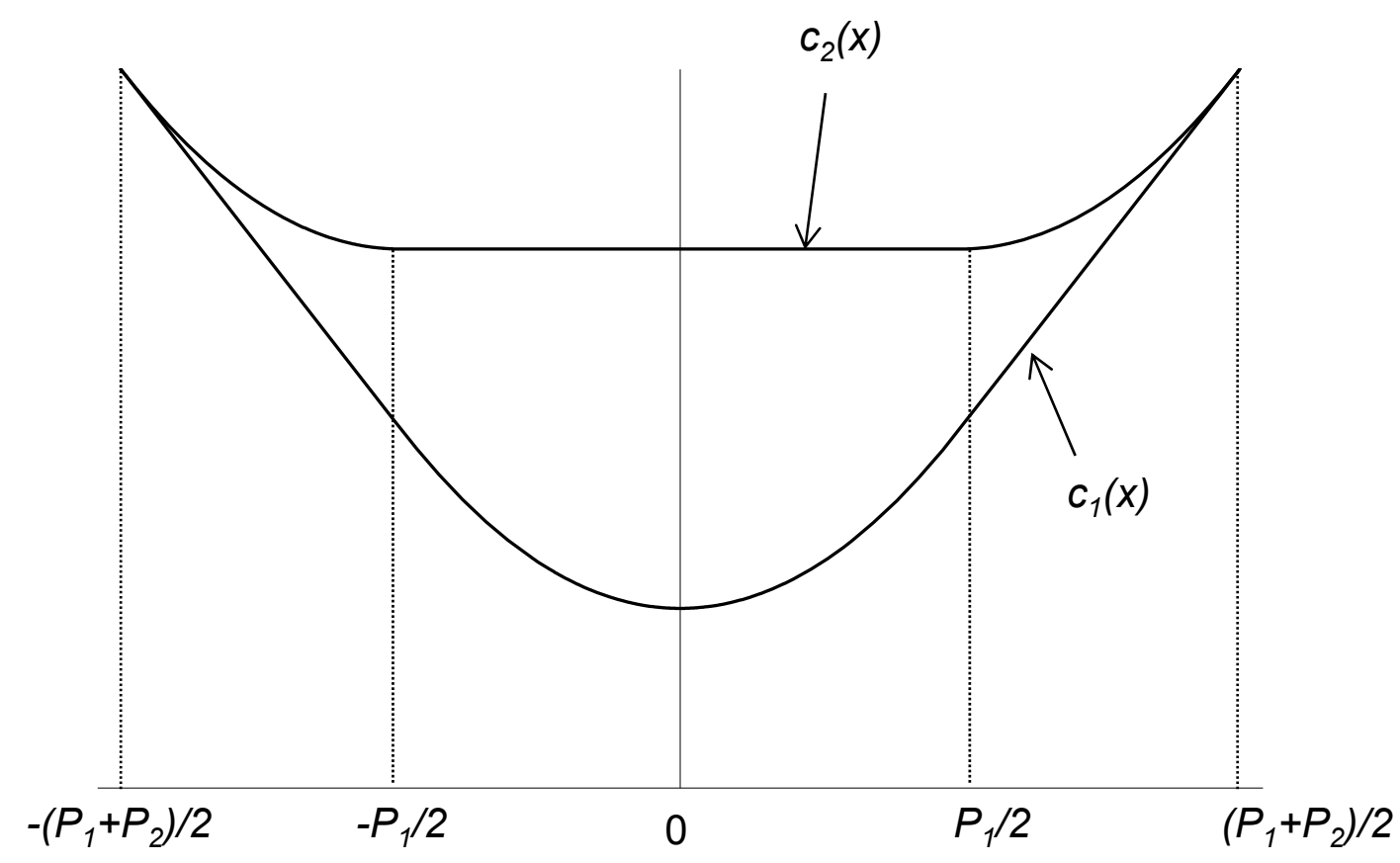

Figure 3: Travel cost functions in the segregated city 


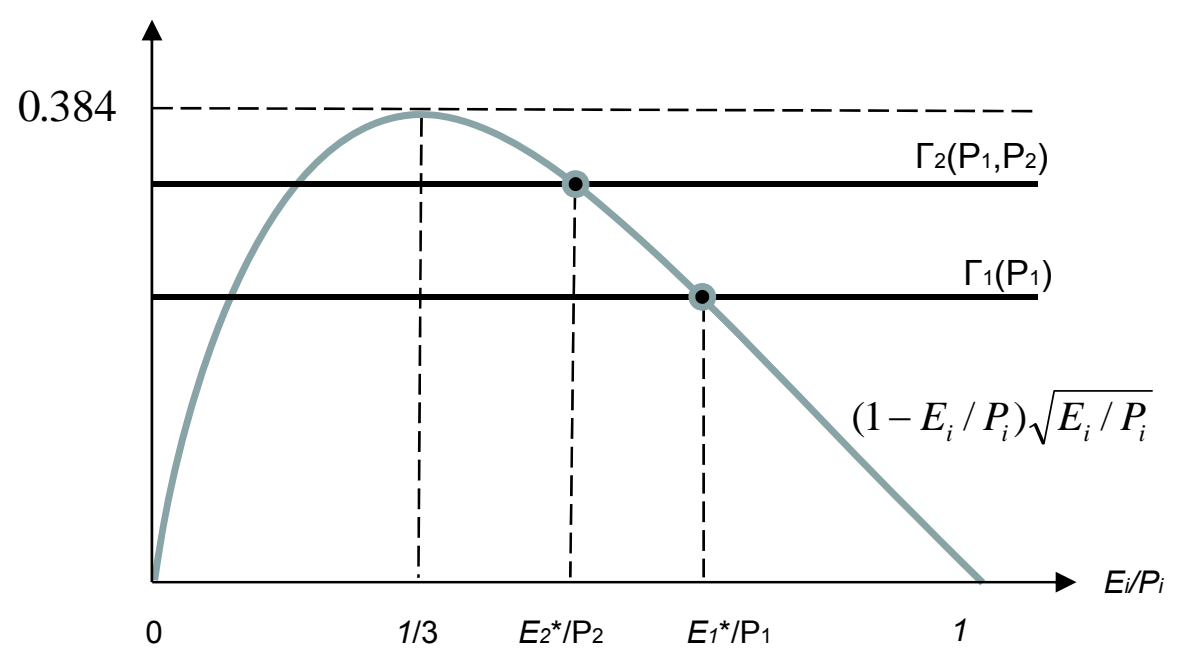

Figure 4: Urban equilibrium with two populations 

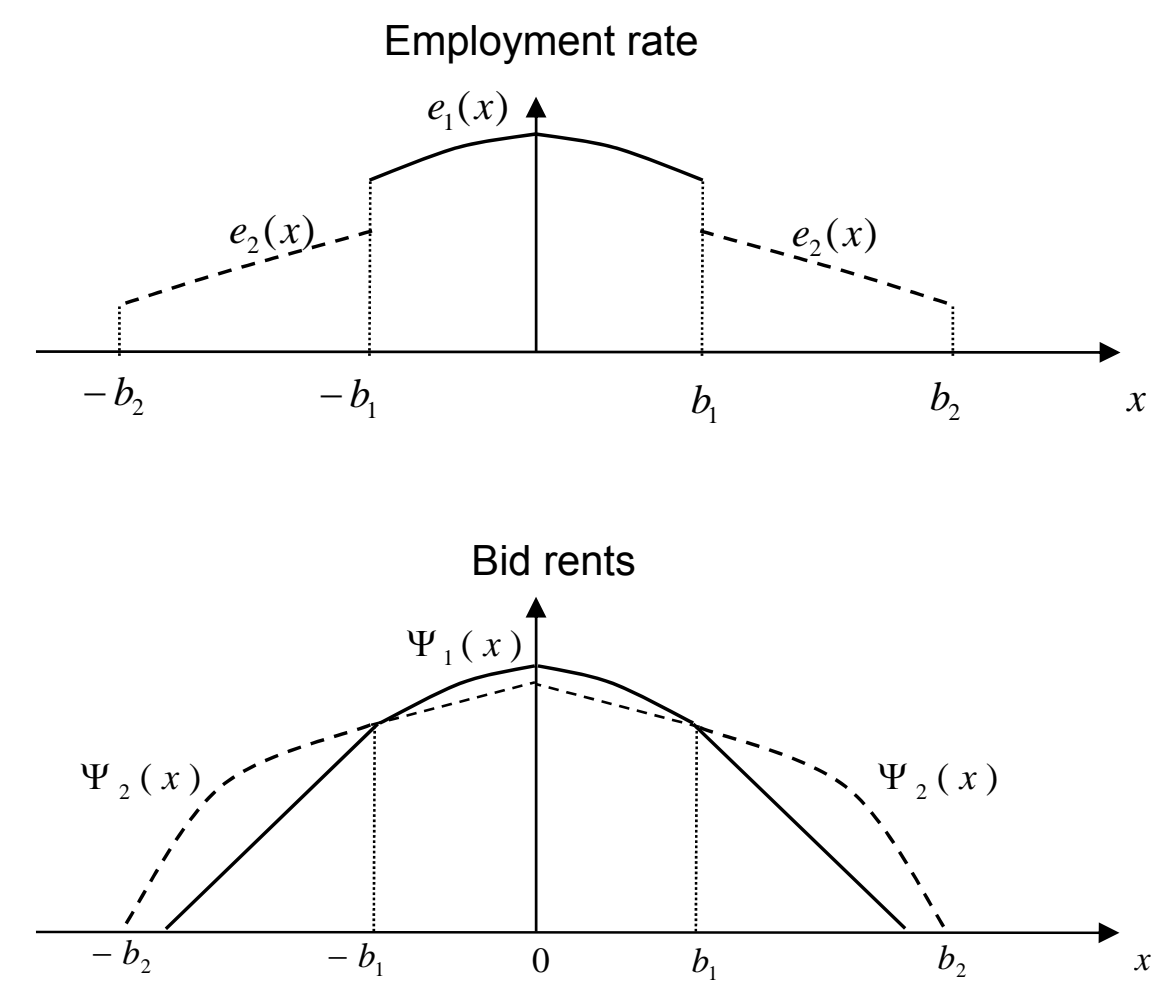

Figure 5: Urban equilibrium with two populations and no network-size effects Population 1 at the center (solid lines), population 2 at city edges (dashed lines) 


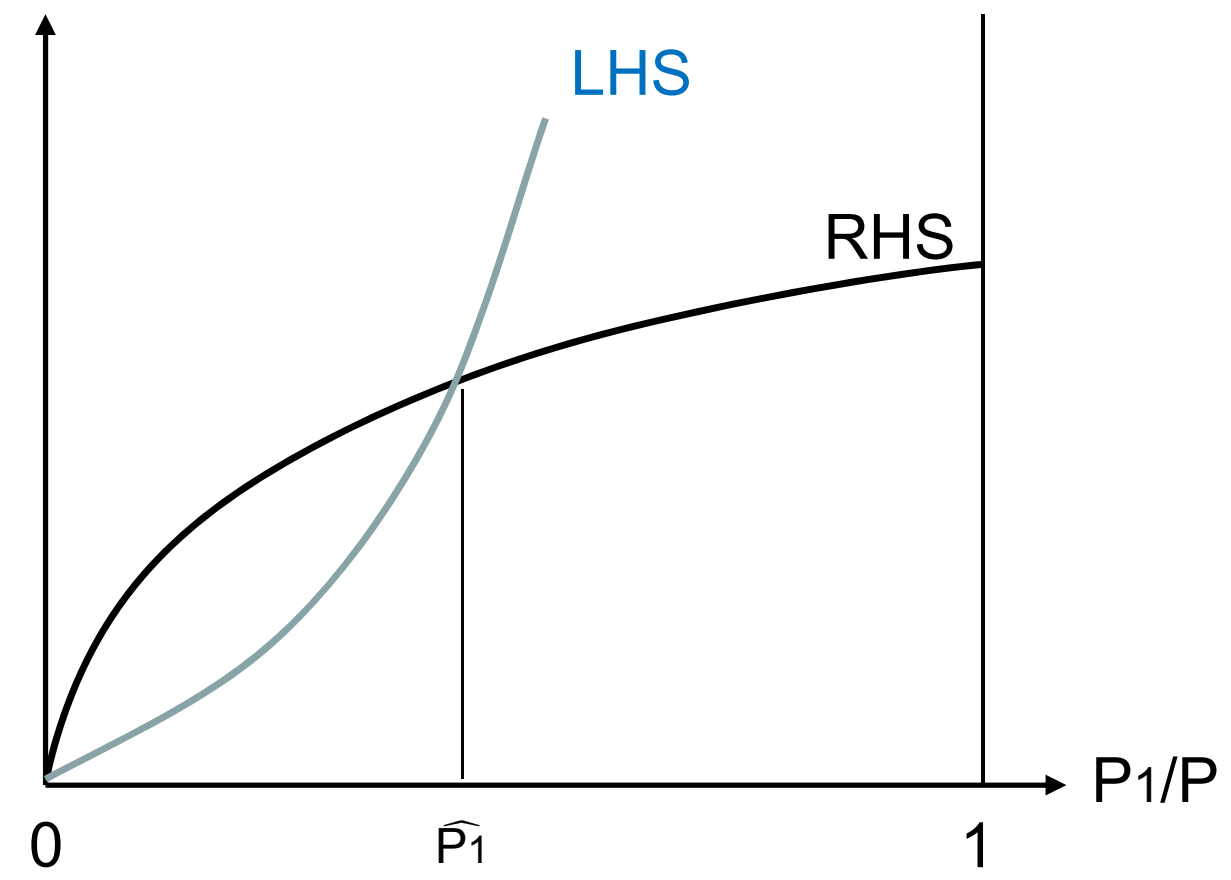

Figure 6: Equation (4) 
Two population equilibrium: bid rent, employment, number of interactions (log)
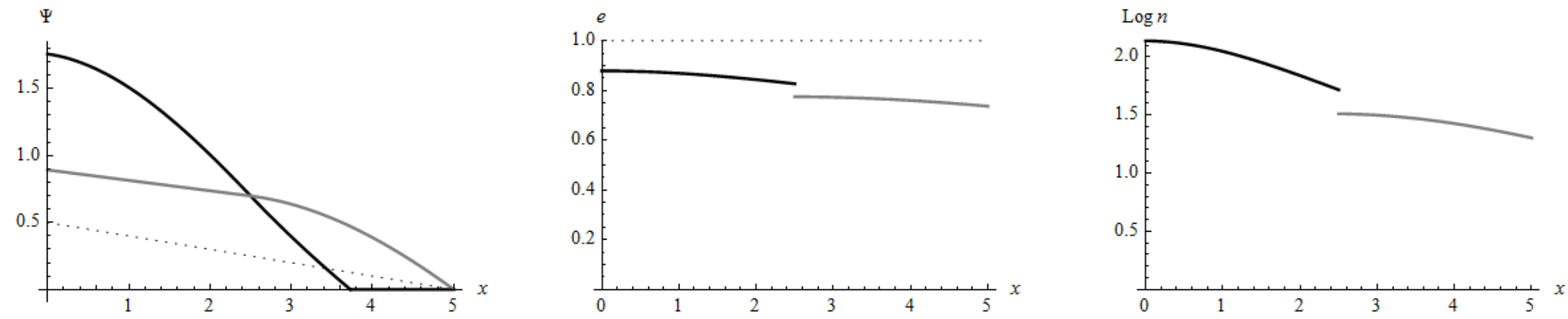

Equilibrium (solid): $\mathrm{E} 1 / \mathrm{P} 1=0.861, \mathrm{E} 2 / \mathrm{P} 2=0.762, \mathrm{u} 1=5.976$, u2=5.162.

Equilibrium without job uncertainty (dotted): E1/P1=E2/P2=1., u1=9.5.

Parameters: $\mathrm{P} 1=5, \mathrm{P} 2=5, \mathrm{w}=10, \quad \alpha=0.1, \quad \beta=0.1, \mathrm{t}=0.1, \tau=0.1, \quad \theta=0$

Figure 7: Urban equilibrium with two populations without network size effect $(\theta=0)$ 
Two population equilibrium: bid rent, employment, number of interactions (log)
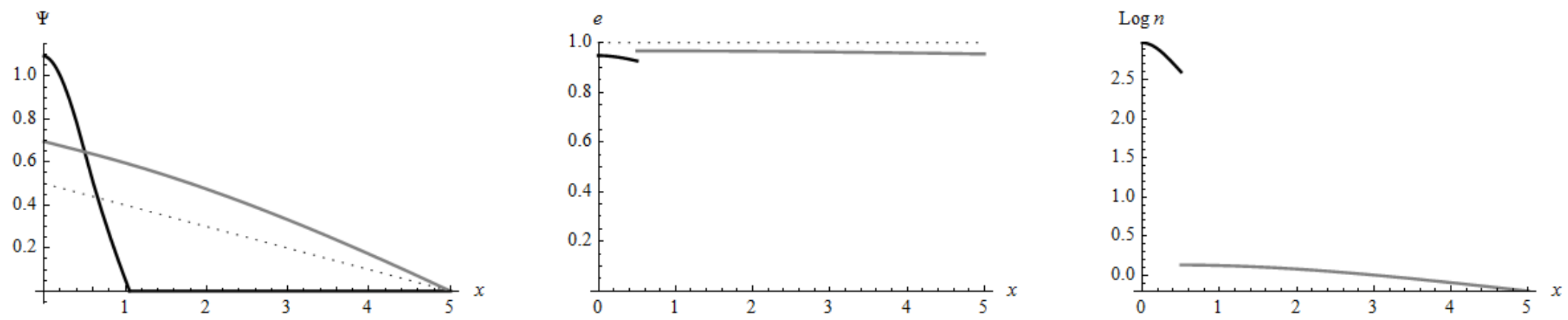

Equilibrium (solid): $\mathrm{E} 1 / \mathrm{P} 1=0.941, \mathrm{E} 2 / \mathrm{P} 2=0.963, \mathrm{u} 1=7.901, \mathrm{u} 2=8.664$.

Equilibrium without job uncertainty (dotted): $\mathrm{E} 1 / \mathrm{P} 1=\mathrm{E} 2 / \mathrm{P} 2=1$. , u1=9.5.

Parameters: $\mathrm{P} 1=1, \mathrm{P} 2=9, \mathrm{w}=10, \quad \alpha=0.1, \quad \beta=0.1, \quad \mathrm{t}=0.1, \quad \tau=0.1, \quad \theta=1.5$

Figure 8: Urban equilibrium with two populations and network-size effects 


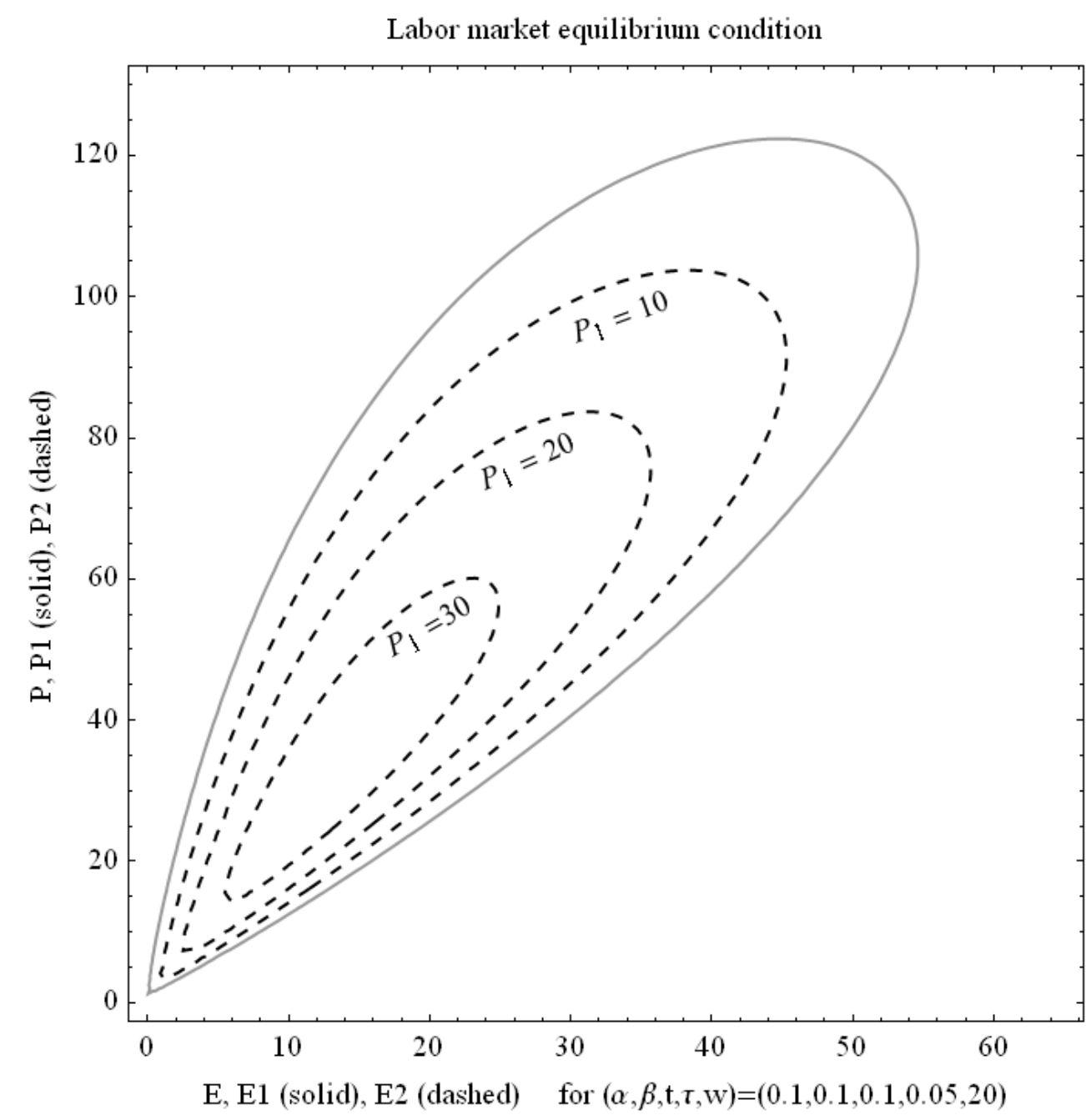

\section{Figure 9: Labor market conditions with directed search}

Each curve displays the locus of aggregate employment and population size.

For one population the locus E-P is shown by the solid curve. For a population size $\mathrm{P}$, the high employment equilibrium lies on the right hand branch of the curve. For two populations, the locus E1-P1 for the central population 1 is shown by the same solid curve while the locus E2-P2 for the peripheral population 2 is displayed by the dashed curve. Each dashed curve corresponds to a specific size of the population 1 . 

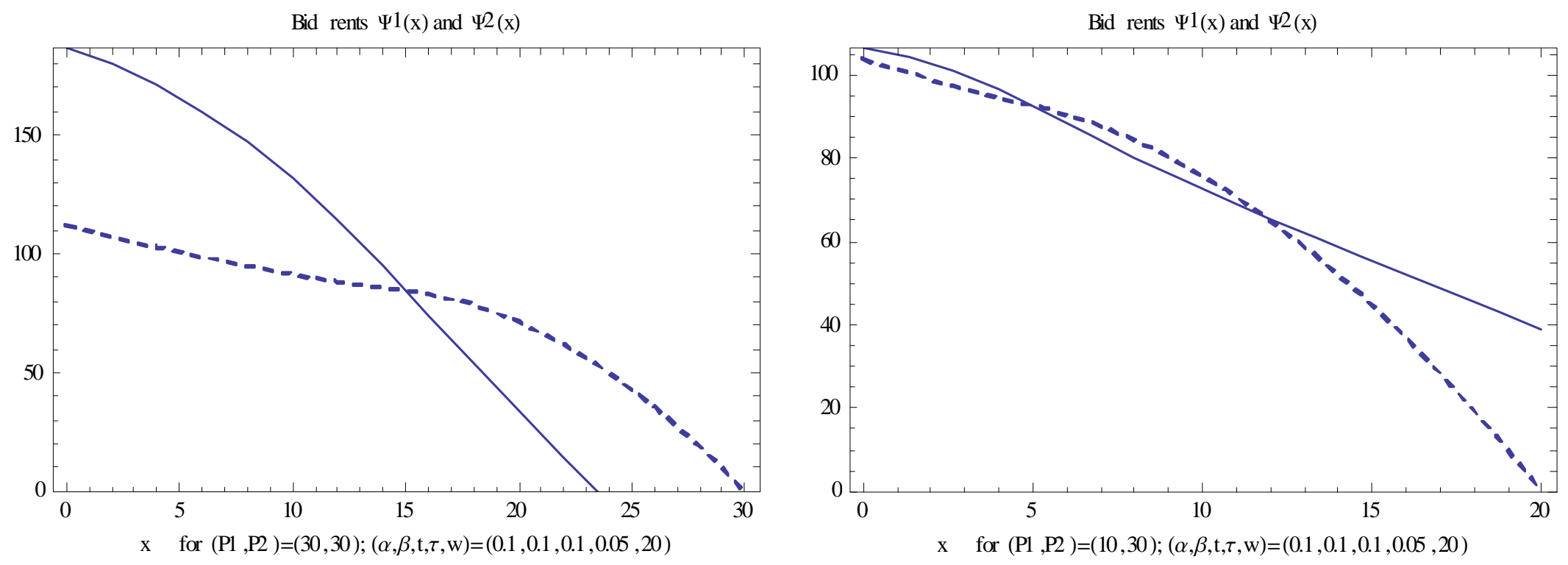

Figure 10: Bid rents may cross twice 
Directed Search Equilibrium with Two Populations : bid rent, employment, number of interactions
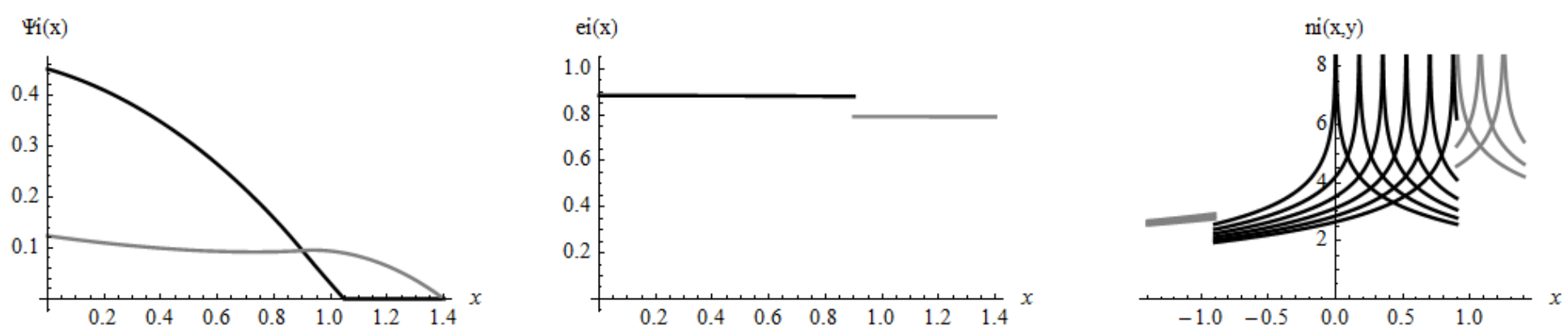

$\mathrm{E} 1 / \mathrm{P} 1=0.883, \mathrm{E} 2 / \mathrm{P} 2=0.792, \mathrm{u} 1=15.218, \mathrm{u} 2=7.416$.

Parameters: $\mathrm{P} 1=1.8, \mathrm{P} 2=1 ., \mathrm{w}=10, \quad \beta=0.1, \mathrm{t}=0.1, \tau=0.1, \alpha(\mathrm{P})=0.5 * \mathrm{P}^{\wedge} 0$

Figure 11: Directed search with no network-size effects and employment higher close to the CBD 

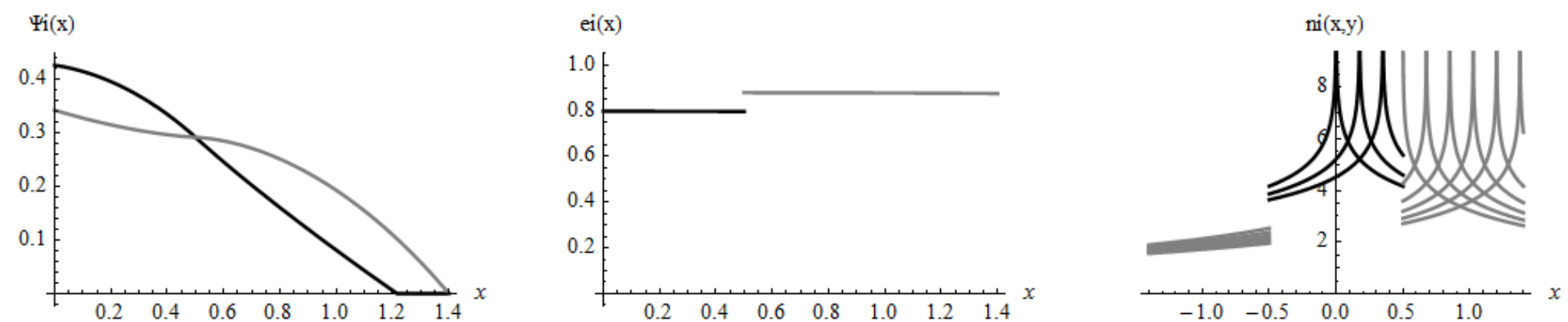

$\mathrm{E} 1 / \mathrm{P} 1=0.798, \mathrm{E} 2 / \mathrm{P} 2=0.878, \mathrm{u} 1=7.439, \mathrm{u} 2=15.055$.

Parameters: $P 1=1, \quad P 2=1.8, \quad w=10, \quad \beta=0.1, \quad t=0.1, \quad \tau=0.1, \quad \alpha(P)=0.5 * P^{\wedge} 0$

Figure 12: Directed search with no network-size effects and employment higher in the periphery 
Directed Search Equilibrium with Two Populations : bid rent, employment, number of interactions
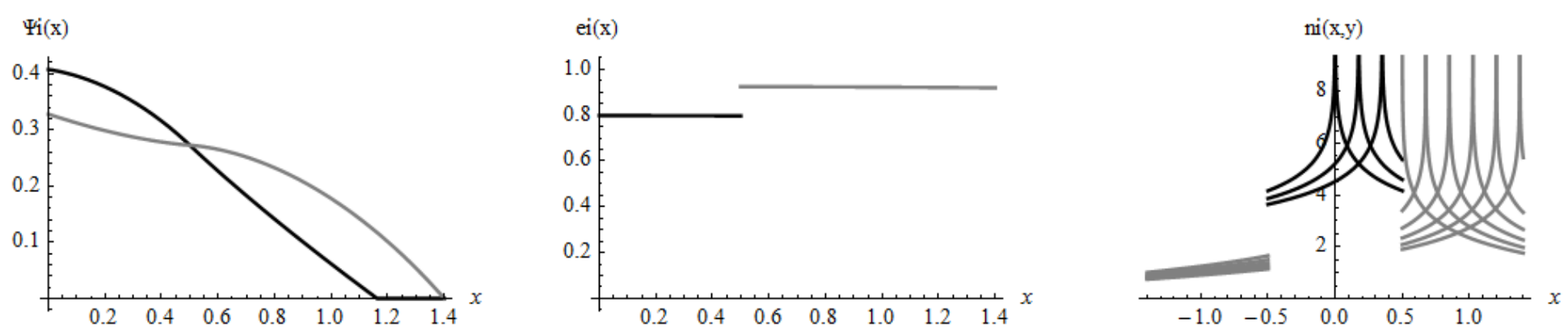

$\mathrm{E} 1 / \mathrm{P} 1=0.798, \mathrm{E} 2 / \mathrm{P} 2=0.923, \mathrm{u} 1=7.459, \mathrm{u} 2=16.027$

Parameters: $\mathrm{P} 1=1, \mathrm{P} 2=1.8, \mathrm{w}=10, \quad \beta=0.1, \mathrm{t}=0.1, \tau=0.1, \alpha(\mathrm{P})=0.5 * \mathrm{P}^{\wedge} 1$

Figure 13: Directed search with network-size effects 